Cuadernos de Filología Clásica. Estudios Latinos

ISSN: 1131-9062

http://dx.doi.org/10.5209/CFCL.56184

\title{
'Arrepentirse' en el Nuevo Testamento en griego y en latín: el empleo de las construcciones con verbo soporte en la Vulgata ${ }^{1}$
}

\author{
José Miguel Baños²; Ma Dolores Jiménez López ${ }^{3}$
}

Recibido: 21 de diciembre de 2016 / Aceptado: 27 de abril de 2017

Resumen. En este trabajo nos proponemos analizar las razones lingüísticas por las que los verbos

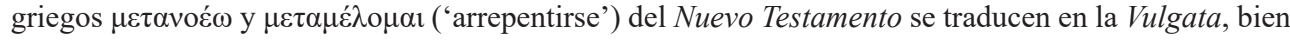
mediante un verbo simple (paenitere), bien, lo más frecuente, mediante distintas colocaciones: paenitentiam agere, paenitentiam habere, paenitentiā ductus y paenitentiā motus. Para profundizar en los criterios que guían la traducción latina, analizaremos, por un lado, las diferencias entre $\mu \varepsilon \tau \alpha v o \varepsilon ́ \omega$ y

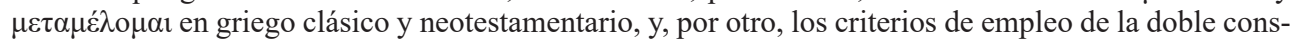
trucción sintáctica de paenitere (impersonal y personal) y de las distintas colocaciones con paenitentia en el Nuevo Testamento y a lo largo de la historia del latín.

Palabras clave: paenitentia; colocación; verbo soporte; griego; latín; Nuevo Testamento; traducción.

\section{[en] 'To repent' in the New Testament in Greek and Latin: the use of constructions with a support verb in the translation of the Vulgate}

\begin{abstract}
In this paper, our purpose is to analyze the linguistic reasons why the Greek verbs of the New Testament $\mu \varepsilon \tau \alpha \nu o \varepsilon ́ \omega$ and $\mu \varepsilon \tau \alpha \mu \varepsilon \dot{\lambda}{ }_{0} \mu \alpha 1$ ( 'to repent') are translated in the Vulgate, either as a simple verb (paenitere), or, most frequently, as different collocations: paenitentiam agere, paenitentiam habere, paenitentia ductus and paenitentia motus. In order to understand better the criteria that guide the Latin translation, we will analyze, on the one hand, the differences between $\mu \varepsilon \tau \alpha v o \varepsilon ́ \omega$ and $\mu \varepsilon \tau \alpha \mu \varepsilon ́ \lambda o \mu \alpha$, and, on the other hand, the criteria for using the double syntactic construction of paenitere (impersonal and personal) and the different collocations with paenitentia in the New Testament and throughout the history of Latin.
\end{abstract}

Key words: paenitentia; collocation; support verb; Ancient Greek; Latin; New Testament; translation.

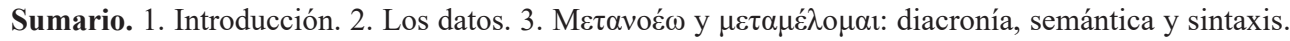
4. La traducción latina mediante colocaciones con paenitentia. 5. La traducción mediante el verbo paeniteo / paenitet. 6. Conclusiones. 7. Referencias bibliográficas.

Cómo citar: Baños Baños, J.M. \& Jiménez López, M.D., «'Arrepentirse’ en el Nuevo Testamento en griego y en latín: el empleo de las construcciones con verbo soporte en la Vulgata», Cuad. Filol. Clásc. Estud. Lat. 37.1 (2017), 11-32.

\footnotetext{
Este trabajo se inscribe en el marco del proyecto de investigación FFI2013-47357-C4-3.

Departamento de Filología Latina de la UCM

Email:jmbanos@ucm.es.

3 Departamento de Filología, Comunicación y Documentación de la UAH

Email: mdolores.jimenez@uah.es.
} 


\section{Introducción}

1.1. Las denominadas construcciones con verbo soporte son colocaciones verbonominales que se definen en la Nueva Gramática de la Lengua Española como «grupos verbales semilexicalizados de naturaleza perifrástica constituidos por un verbo y un sustantivo abstracto que lo complementa. Estos grupos admiten muchas veces [...] paráfrasis formadas con verbos relacionados morfológica o léxicamente con dicho sustantivo: dar un paseo ('pasear'), echar una carrera ('correr'), hacer alusión ('aludir'), etc.» (NGLE 2009, 57).

En el caso del latín, aunque el análisis de estos predicados complejos quedó durante tiempo relegado al ámbito de la estilística (Hofmann-Szantyr 1965, 754-756), como si fuera un rasgo propio sobre todo del latín coloquial (López Moreda 1987, 165), en la actualidad diversos estudios ${ }^{4}$ han puesto de manifiesto la importancia cuantitativa y cualitativa de estas construcciones, que tienen por lo general una justificación funcional (léxica, semántica, morfo-sintáctica) y que están presentes en prosa y en verso, con una mayor frecuencia, por ejemplo, en la historiografía (César, Salustio, Livio o la Historia Augusta) que en textos más vulgares como la Cena de Trimalción de Petronio o la Peregrinatio Aetheriae (Baños, en pr.b).

1.2. Precisamente, la frecuencia de empleo de las construcciones con verbo sopor$t^{5}$ (en adelante, CVS) supone uno de los rasgos diferenciadores más importantes del latín clásico respecto al griego antiguo: allí donde el latín emplea un predicado analítico como gratias ago, odio habeo o consilium capio el griego prefiere por lo

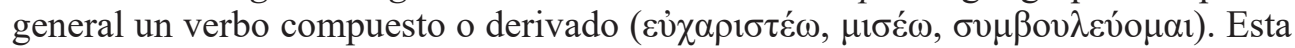
diferencia se pone claramente de manifiesto desde perspectivas muy diversas:

(i) al comparar, por ejemplo (Baños 2015a), la frecuencia de empleo del verbo

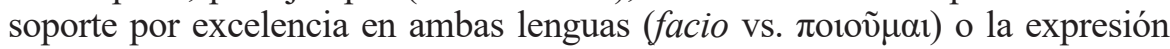
concreta de un mismo predicado semántico ('hacer la guerra' y 'combatir') allí donde las dos lenguas disponen de la posibilidad de expresión mediante una

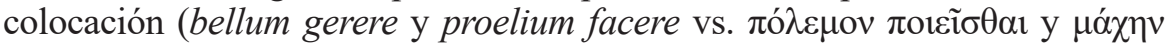

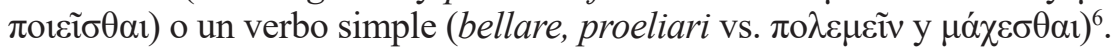

(ii) al analizar la frecuencia absoluta de las CVS en corpus textuales similares desde el punto de vista del contenido y género literario: así, por ejemplo (López Martín 2016, 14), por cada colocación verbo-nominal en Jenofonte (HG1 y $A n .1)$ se documentan cinco en un corpus de extensión similar en César (Gall.1 y civ.1).

1.3. Esta diferencia de empleo entre las dos lenguas tiene importantes consecuencias en la traducción del Nuevo Testamento (NT), tal como se ha puesto de manifiesto a

$4 \quad C f$., entre otros, Hoffmann (1996, 203), Pinkster (2015, 74-77) y Baños (2016, en pr.a). En Jiménez Martínez (2016, 37-106) se ofrece un buen estado de la cuestión sobre el concepto mismo de colocación y construcciones con verbo soporte, y sobre los estudios desarrollados al respecto en el ámbito del latín.

5 Al igual que Flobert (1996), utilizamos el término «verbo soporte» para referirnos no sólo a los verbos más generales (facere, habere, esse, dare, etc.), que configuran colocaciones más neutras (del tipo proelium facere, impetum facere), sino también a aquellos más específicos, que añaden por lo general matices aspectuales o diatéticos (proelium committere, inire, conserere; impetum sustinere, etc.). Rosén (1981, 130), utiliza la expresión «Analitic Forms (Periphrasis)» con el mismo alcance.

6 Los datos del griego proceden de los trabajos de Jiménez López $(2011,2012,2016)$. 
partir del análisis comparado del texto griego y latino del Evangelio de Mateo (Baños 2015b): a pesar de que Jerónimo (epist.57.5-6), en su revisión de una versión previa de la Vetus Latina (Bogaert 1988, 157), pretende una traducción fiel al texto griego (verbum e verbo), las construcciones con verbo soporte son mucho más frecuentes en la Vulgata que en el original griego. El famoso pasaje evangélico de (1) ilustra muy bien esta diferencia: allí donde el texto griego de Mateo presenta cuatro formas verbales, la versión de Jerónimo ofrece tres colocaciones:

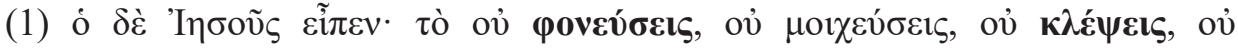

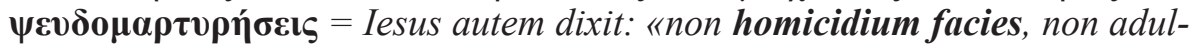
terabis, non facies furtum, non falsum testimonium dices» («Jesús le contestó: - "No matarás, no cometerás adulterio, no robarás, no darás falso testimonio"», Eu.Matt.19.18).

Pues bien, de cada cuatro CVS de la versión latina de la Vulgata, tres de ellas no corresponden a colocaciones verbo-nominales en el texto griego de Mateo sino, tal como ilustra el pasaje (1), a un predicado verbal sintético (normalmente un verbo compuesto o derivado). En tales casos, a pesar de que en latín existía también la posibilidad de traducción mediante un verbo simple, Jerónimo prefiere un predicado analítico, es decir, una colocación verbo-nominal, porque entiende que es la forma de expresión más clásica en latín o la de uso más generalizado en la lengua del siglo IV (Baños 2015b, 67-69).

Este principio de traducción supone un rasgo diferenciador claro entre la versión de Jerónimo de los evangelios y las versiones anteriores de la Vetus Latina ${ }^{8}$. Y es que, como muestra el pasaje (2), en no pocos casos en que en la Vulgata se emplea una colocación, la mayoría de las versiones de la Vetus Latina, en su afán de traducción literal del texto griego, recurre en latín a un verbo simple?

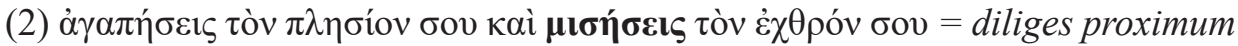
tuum et odio habebis [VL Ital.: odies; Afr.: odibis] inimicum tuum («amarás a tu prójimo y odiarás a tu enemigo», Eu.Matt.5.43).

Para el texto griego y latino del NT seguimos la edición bilingüe de Nestle-Aland (2014). Para las cuestiones de crítica textual del texto latino, hemos tenido presente, además, las ediciones de Wordsworth-White $\left(1957^{2}\right)$ y Weber-Gryson (19944). Cuando hemos considerado oportuno añadir una traducción en español, hemos utilizado la de Mateos-Alonso Schökel (Madrid, Ediciones Cristiandad, 1987²) para el NT. En los ejemplos de autores clásicos la traducción es propia.

8 Dada la gran variedad textual y el carácter poco uniforme de los testimonios, para los evangelios, siguiendo la edición de la Vetus Latina de Jülicher-Matzkow-Aland (1963-1972), distinguiremos de manera general entre la versión Afra (VL Afr.) e Itala (VL Ital.). Para no hacer interminables las referencias bibliográficas sobre el latín del Nuevo Testamento, remitimos a las actualizaciones de Elliot (1992) y Burton (2013) y a la reciente monografía de Houghton (2016). De entre estos estudios, además de la monografía de Burton (2000), siguen siendo una referencia obligada los trabajos de Vineis (1971-1974).

9 Para el análisis de las distintas traducciones latinas (odi, odio sum, odio habeo) del verbo $\mu$ tбé $\omega$ en el NT, cf. Baños-Jiménez (2017). Los ejemplos similares a (2), de CVS en la Vulgata y verbo simple en la Vetus

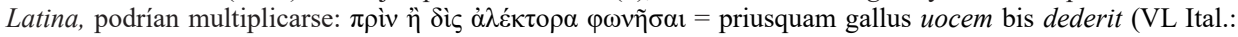

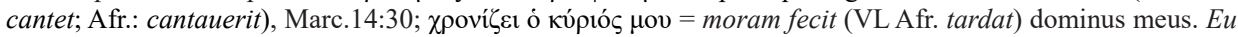

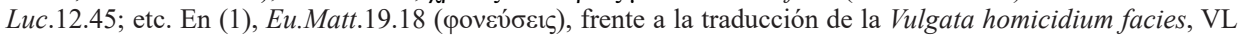
Ital: occides, VL Afr. occidis. Esta diferencia fundamental no deja de ser un ejemplo más en la Vetus Latina de «la práctica de un literalismo, variable según los traductores, pero generalmente extremo, que ocasiona un profundo influjo griego» (Moreno Hernández 1992, 405). 
1.4. Por supuesto, más allá de la frecuencia de las CVS, interesa comprobar, entre otros aspectos, hasta qué punto estos principios generales de traducción del texto griego de Mateo son comunes a los cuatros evangelios y si existen diferencias en el empleo de las CVS en el resto de libros del Nuevo Testamento ${ }^{10}$, libros en cuya traducción ya no intervino directamente Jerónimo. Para responder a estas y otras cuestiones se hace necesario profundizar en el análisis puntual de determinadas colocaciones latinas de uso frecuente, sobre todo si dichas colocaciones alternan en la Vulgata latina con un verbo simple.

Este es el objetivo último de nuestro trabajo. En él, nos proponemos analizar el predicado verbal 'arrepentirse', que en el texto griego del Nuevo Testamento

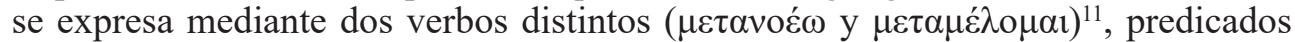
que se vierten al latín, bien mediante un verbo simple (paenitere), bien, lo más frecuente, mediante distintas colocaciones: paenitentiam agere, paenitentiam habere, paenitentiā ductus, paenitentiā motus. Intentaremos mostrar que existen razones lingüísticas que justifican la elección de cada colocación concreta y de paenitere en la traducción de $\mu \varepsilon \tau \alpha v o \varepsilon ́ \omega$ y $\mu \varepsilon \tau \alpha \mu \varepsilon ́ \lambda o \mu \alpha$, dos verbos que presentan a su vez diferencias morfológicas, de significado y de construcción sintáctica. La perspectiva diacrónica será, en este sentido, uno de los hilos conductores de nuestra exposición, tanto en el análisis de los verbos griegos, como de paenitere y de las distintas CVS latinas con paenitentia documentadas en el NT.

\section{Los datos}

2.1. En los ejemplos de (3) a (8) se ilustran las distintas formas de traducción de los

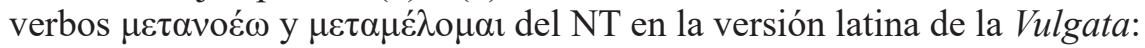

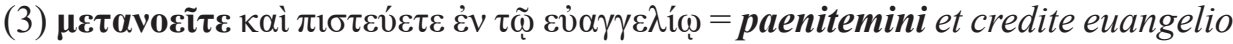
(«Enmendaos y tened fe en esta buena noticia», Eu.Marc.1.15).

10 Nuestro estudio se limita al Nuevo Testamento, sobre todo, por razones metodológicas: como es sabido, «while the Vulgate of the Old Testament represents something genuinely new and unique, an attempt to translate from Hebrew and Aramaic into Latin, the Vulgate New Testament is simply another stage in the development of the Latin Bible» (Burton 2013, 182). Aunque en ocasiones haremos referencia al Antiguo Testamento (AT), conviene tener presente que entre el texto griego original del NT y el griego de traducción de los LXX del AT hay en muchos casos tres siglos de diferencia. Por último, no hay que olvidar el carácter no uniforme de la versión de la Vulgata en el caso del NT: Jerónimo revisó sin duda la traducción de los evangelios, pero no así el resto de libros, a cargo de su discípulo Rufino de Siria (Bogaert 1988, 159; 2013, 517-518; García de la Fuente 1990, 96).

11 Un tercer verbo formaría parte de este campo semántico: غ̇ंı $\tau \rho \varepsilon ́ \varphi \omega$ ('convertirse'), que se traduce siempre en el NT (36 ejs.) mediante el calco semántico conuerto y no por una CVS, razón por la que no es objeto de estudio

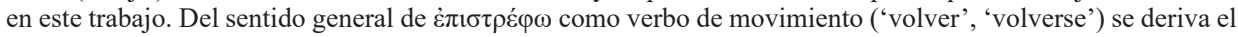
significado religioso de 'convertirse', con el que entra en confluencia con $\mu \varepsilon \tau \alpha v \varepsilon ́ \omega$ en el NT (Heikkinen 1967). Laubach y Goetzmann (2012) explican bien la diferencia entre ambos verbos: غ̇ंı $\tau \rho \varepsilon \dot{\varphi} \varphi \omega$ en el AT se emplea,

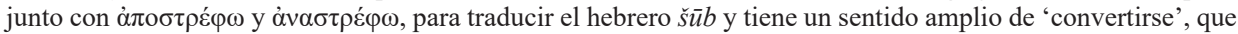

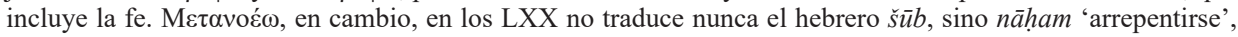
entendido como un cambio de mentalidad. La diferencia entre ambos verbos en el NT se constata cuando se

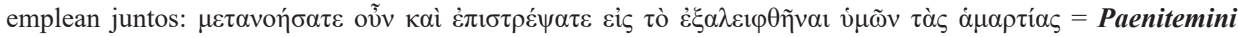
igitur et conuertimini, ut deleantur uestra peccata («Por tanto, arrepentíos y convertíos para que se borren vuestros pecados», Act.Ap.3.19); $c f$. también, Act.Ap.26.20. Frente a la regularidad de traducción de غ̇ंı $\sigma \rho \varepsilon \dot{\varphi} \varphi \omega$ por converto en el NT y su diferenciación de $\mu \varepsilon \tau \alpha v o \varepsilon ́ \omega$, en el AT tanto غ̇ंı

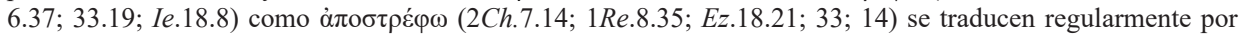
paenitentiam agere, con la excepción, en el caso de غ̇ंı $\_\rho \dot{\varphi} \varphi \omega$, de Iu.5.19, traducido por paenituerunt. 


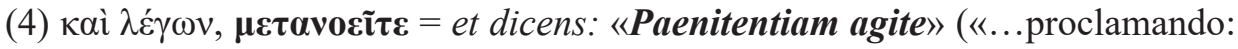
-Enmendaos», Eu.Matt.3.2).

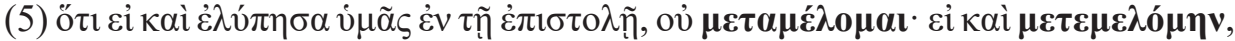

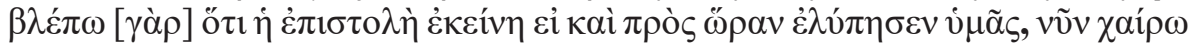
= Quoniam etsi contristaui uos in epistula, non me paenitet; etsi paeniteret -uideo quod epistola illa, etsi ad horam, uos contristauit-nunc gaudeo («Por eso, aunque os causé pena con mi carta, no lo siento; antes lo sentía, viendo que aquella carta os dolió, aunque fue por poco tiempo», 2Ep.Cor.7.8-9).

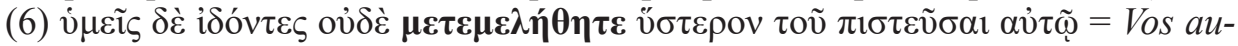
tem uidentes nec paenitentiam habuistis postea, ut crederetis ei («Pero vosotros, ni aún después de aquello habéis sentido remordimiento ni le habéis creído», Eu.Matt.21.32).

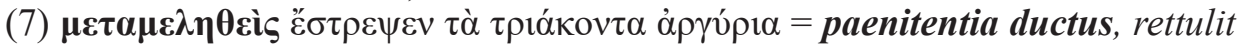
triginta argenteos («[Judas] sintió remordimientos y devolvió las treinta monedas de plata», Eu.Matt.27.3).

(8) («pero después sintió remordimiento y fue», Eu.Matt.21.29).

A la luz de estos ejemplos, da la impresión de que la libertad de traducción en la Vulgata no tiene límites: por un lado, un mismo verbo latino (paenitere) sirve como traducción tanto de $\mu \varepsilon \tau \alpha v o \varepsilon ́ \omega$ (3) como de $\mu \varepsilon \tau \alpha \mu \varepsilon ́ \lambda o \mu \alpha \imath$ (5). Por otro, desde la perspectiva del griego, en el caso de $\mu \varepsilon \tau \alpha \nu o \varepsilon ́ \omega$, una misma forma verbal ( $\mu \varepsilon \tau \alpha \nu o \varepsilon i \tau \varepsilon)$ es traducida indistintamente por un verbo simple, paenitemini (3), y por una construcción con verbo soporte, paenitentiam agite (4). Y en el caso de $\mu \varepsilon \tau \alpha \mu \varepsilon ́ \lambda o \mu \alpha 1$, este verbo se vierte al latín de cuatro formas distintas: por paenitere (5) y por tres colocaciones diferentes: paenitentiam habuistis (6), paenitentiā ductus (7) y paenitentiā motus (8).

$\mathrm{Y}$, sin embargo, un análisis más detenido de los ejemplos muestra que, por encima de esta aparente libertad, existen razones lingüísticas que justifican en mayor o menor medida la elección de cada traducción. En otras palabras, como intentaremos demostrar, la Vulgata emplea el verbo paenitere (en su doble construcción, personal o impersonal) o CVS distintas con paenitentia para señalar diferencias de significado y construcción sintáctica de los verbos originales griegos.

2.2. La frecuencia de empleo en el NT tanto de $\mu \varepsilon \tau \alpha \nu o \varepsilon ́ \omega$ y $\mu \varepsilon \tau \alpha \mu \varepsilon ́ \lambda o \mu \alpha$ como de sus distintas traducciones latinas constituye ya un primer dato esclarecedor, tal como muestran los datos del Cuadro (1):

Cuadro (1): 'arrepentirse' en el NT en griego y su traducción latina

\begin{tabular}{|c|c|c|c|c|c|c|}
\hline \multicolumn{2}{|c|}{ verbo griego } & \multicolumn{5}{|c|}{ traducción latina } \\
\hline & & \multirow{3}{*}{$\begin{array}{c}\text { verbo simple } \\
\text { paenitere }\end{array}$} & \multicolumn{4}{|c|}{ colocación } \\
\hline & & & \multicolumn{2}{|c|}{ paenitentiam +} & \multicolumn{2}{|c|}{ paenitentia $(\mathrm{abl})+}$. \\
\hline & & & agere & habere & ductus & motus \\
\hline$\mu \varepsilon \tau \alpha \nu \circ \varepsilon \dot{\varepsilon} \omega$ & 34 & 5 & 29 & - & - & - \\
\hline$\mu \varepsilon \tau \alpha \mu \varepsilon \dot{\varepsilon}{ }_{0} \mu \alpha \imath$ & 6 & 3 & - & 1 & 1 & 1 \\
\hline Total & 40 & 8 & 29 & 1 & 1 & 1 \\
\hline
\end{tabular}


De entrada, desde la perspectiva del texto griego, se pone de manifiesto el empleo predominante del verbo $\mu \varepsilon \tau \alpha v o \varepsilon ́ \omega$ (34 ejemplos), frente al uso ocasional (6 ejem-

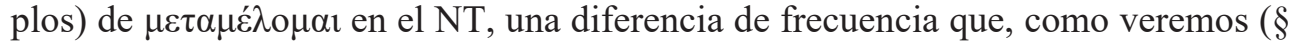
3.2), guarda relación con el significado de $\mu \varepsilon \tau \alpha \mu \varepsilon ́ \lambda o \mu \alpha 1$.

Por otra parte, desde la perspectiva de la versión latina de la Vulgata, hay una CVS predominante (paenitentiam agere) que, siempre que aparece en el NT, es traducción del verbo griego $\mu \varepsilon \tau \alpha v o \varepsilon ́ \omega$, mientras que las otras tres CVS, además de excepcionales (un solo ejemplo de cada una), son, en todo caso, traducción de $\mu \varepsilon \tau \alpha \mu \varepsilon ́ \lambda o \mu \alpha 1$. Hay, pues, una elección consciente de CVS latinas distintas para la traducción de cada uno de los verbos griegos, lo que invita a pensar en diferencias de significado entre $\mu \varepsilon \tau \alpha \nu o \varepsilon ́ \omega$ y $\mu \varepsilon \tau \alpha \mu \varepsilon ́ \lambda o \mu \alpha$.

Para comprobarlo, vamos a analizar en primer lugar las diferencias en la frecuen-

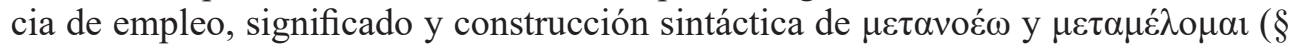
3), tanto en griego clásico como neotestamentario, como paso previo al estudio de su traducción latina en la Vulgata, bien mediante colocaciones (§ 4), que es la opción predominante (32 de los 40 ejemplos), bien mediante el verbo paenitere $(\S 5)$. En uno y otro caso, constataremos, además, importantes diferencias entre el latín clásico y tardío.

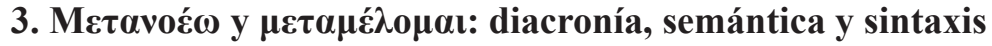

3.1. Los datos sobre $\mu \varepsilon \tau \alpha v o \varepsilon ́ \omega$ y $\mu \varepsilon \tau \alpha \mu \varepsilon ́ \lambda o \mu \alpha$ en el NT recogidos en el Cuadro (1) contrastan con el empleo de ambos verbos en el griego de época clásica, tal como muestra el Cuadro (2), en el que, a partir de un amplio corpus de autores en prosa ${ }^{12}$, se compara su frecuencia de empleo en época clásica y helenística:

Cuadro (2): $\mu \varepsilon \tau \alpha v o \varepsilon ́ \omega$ y $\mu \varepsilon \tau \alpha \mu \varepsilon ́ \lambda o \mu \alpha$ en la prosa de época clásica y de koiné helenística

\begin{tabular}{|c|c|c|c|c|c|c|c|c|c|c|}
\hline & \multicolumn{4}{|c|}{ Prosa clásica } & \multicolumn{6}{|c|}{ Prosa de koiné } \\
\hline & oradores & historiad. & $\mathrm{Pl}$. & Arist. & Polib. & D.S. & Fil. & Jos. & Plut. & NT \\
\hline$\mu \varepsilon \tau \alpha \nu \circ \varepsilon ́ \omega$ & 3 & 2 & 1 & - & 5 & 26 & 35 & 47 & 43 & 34 \\
\hline$\mu \varepsilon \tau \alpha \mu \varepsilon \varepsilon \lambda \varepsilon$ & 27 & 24 & 9 & 1 & 2 & 2 & - & 4 & 5 & - \\
\hline 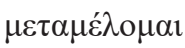 & 0 & 8 & 1 & 3 & 3 & 8 & - & 1 & 22 & 6 \\
\hline
\end{tabular}

El verbo $\mu \varepsilon \tau \alpha v o \varepsilon ́ \omega$ ('percibir o pensar después' y, de ahí, 'cambiar de opinión, arrepentirse') se crea sobre el modelo de $\pi$ povoć $\omega$ ('percibir o pensar antes, prever') $\mathrm{y}$, en consonancia con su etimología ( $c f$. vóos, voć $\omega$ ), expresa una acción intelectual; no se atestigua hasta el s. V a. C., en la Tetralogía Primera atribuida a Antifonte (9), una obra rica en innovaciones lingüísticas. El término apenas se usa entre los prosis-

12 En concreto, en época clásica, además de Platón y Aristóteles, se han analizado los oradores Antifonte, Demóstenes, Esquines, Iseo, Isócrates y Lisias, y los historiadores Heródoto, Tucídides y Jenofonte. El corpus de koiné helenística, está compuesto, junto al NT, por Polibio, Diodoro Sículo, Filón de Alejandría, Flavio Josefo y Plutarco. 
tas clásicos ${ }^{13}$ (6 ejemplos), lo que contrasta con su frecuencia de empleo en el griego de koiné (190 ejemplos).

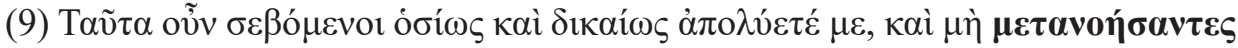

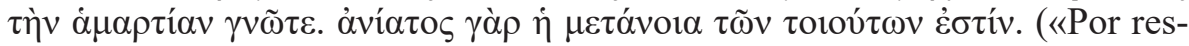
peto, pues a esos principios, absolvedme conforme a la ley divina y la justicia, no sea que cambiéis de opinión y os deis cuenta de vuestro error, pues el arrepentimiento en casos como este no tiene remedio», Antipho2.4.12).

También $\mu \varepsilon \tau \alpha \mu \varepsilon ́ \lambda o \mu \alpha$, compuesto formado a partir de $\mu \varepsilon ́ \lambda \omega$ ('ser objeto de interés o preocupación'), indica, con el prefijo $\mu \varepsilon \tau \alpha$-, la idea de cambio y, de ahí, la de arrepentimiento, pero, como bien señala Thompson (1908), entendido más como un sentimiento de pesar que como una acción puramente intelectual ( $\mu \varepsilon \tau \alpha v o \varepsilon ́ \omega)$. Además, en este verbo hay que distinguir - como veremos también con paenitere en latín ( $\S$ 5.2) - entre la construcción impersonal $\mu \varepsilon \tau \alpha \mu \varepsilon ́ \lambda \varepsilon$, en activa (10a-b), y la construcción

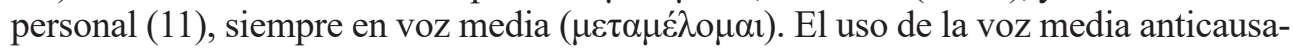
tiva ${ }^{14}$ en la construcción personal es coherente con el significado del verbo: emociones como el pesar o el arrepentimiento ( $\mu \varepsilon \tau \alpha \mu \varepsilon ́ \lambda o \mu \alpha \iota)$, el miedo (

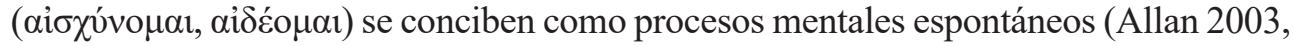
73-76) y su sujeto no es un Agente, sino un Experimentador ${ }^{15}$.

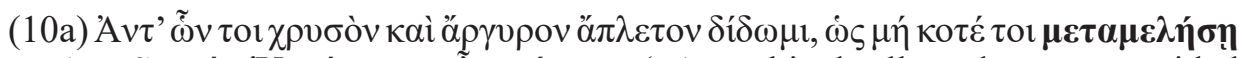

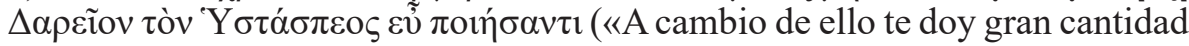
de oro y plata, para que no te arrepientas jamás de haber hecho un favor a Darío, el hijo del Histaspes», Hdt.3.140.23)

(10b) 'H que él se arrepentía de lo ocurrido, cedí», Isoc.17.18.7).

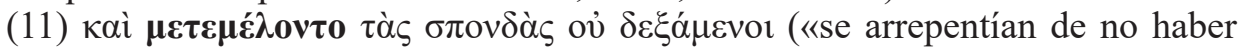
aceptado la paz», Th.4.27.2)

Como muestran los datos del Cuadro (2), en la construcción impersonal (con el Experimentador en caso dativo y la causa del arrepentimiento en genitivo (10b) o

13 Fuera de la prosa solo se documenta, de acuerdo con los datos obtenidos del TLG (Packard Humanities Institute) con Diogenes (versión 3.2.0), un ejemplo de $\mu \varepsilon \tau \alpha v o \varepsilon ́ \omega$ en un fragmento de Sófocles (S.Fr.857.1).

14 Hay dos ejemplos de Heródoto en los que el verbo aparece en voz activa, pero con sentido causativo, pues el objeto de arrepentimiento no aparece en genitivo, sino como sujeto sintáctico en nominativo: $\mathrm{O} \delta \dot{\varepsilon} \pi \alpha \tilde{\varsigma} \varsigma \eta u ̛ \xi \varepsilon \tau o$,

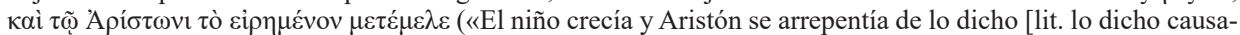
ba pesar a Aristón]», Hdt.6.63.2); $c f$. también, Hdt.9.1.1. Otros ejemplos similares fuera de nuestro corpus: $\dot{\omega} \varsigma$

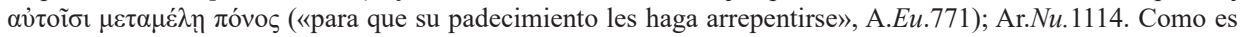
sabido, es frecuente en griego que un verbo exprese diátesis causativa con la voz activa y anticausativa con la voz media ( / 'despertarse', etc.).

15 En un mismo pasaje de Heródoto concurren la construcción impersonal con el Experimentador en dativo

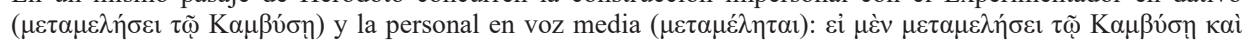

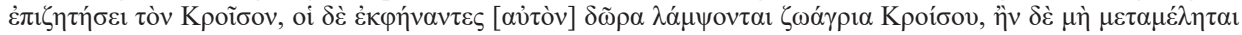

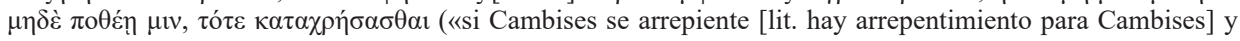
echa de menos a Creso, ellos lo sacarán (de su escondite) y recibirán como recompensa el rescate de Creso, pero si no se arrepintiera ni lo añorara, entonces lo matarían», Hdt.3.36.26). La coordinación en ambos casos con

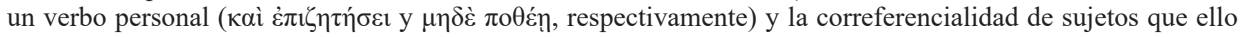
implica constituye un contexto propicio para la extensión de la construcción personal. Para ejemplos similares en latín con paenitet, $c f$. Baños $(2003,64)$. 


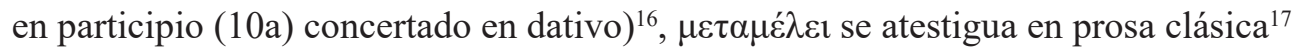
con mucha mayor frecuencia (61 ejs.) que $\mu \varepsilon \tau \alpha v o \varepsilon ́ \omega$ (6 ejs.), situación que se invierte totalmente en el griego de koiné (13 y 190 ejs., respectivamente). En cambio, la construcción personal, $\mu \varepsilon \tau \alpha \mu \varepsilon ́ \lambda o \mu \alpha$, poco habitual en prosa clásica, acaba siendo en época helenística más frecuente que la construcción impersonal.

En conclusión, comparando los datos de los Cuadros (1) y (2), el empleo de

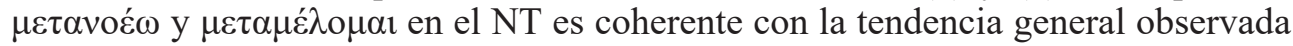

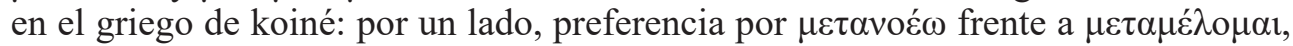

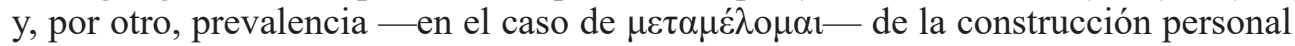
en voz media sobre la impersonal en voz activa.

3.2. Pero, por encima de su frecuencia de empleo en el NT, interesa deternerse en

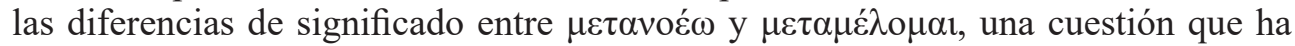
suscitado numerosos estudios en relación, además, con su interpretación teológica. Pues bien, desde el estudio diacrónico de Thompson (1908) o el artículo de Michel (1967) a los recientes de Laubach (2012) y Goetzmann (2012) sobre el NT, hay coin-

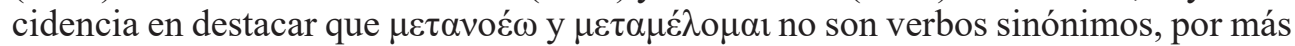
que en contextos puntuales sus diferencias puedan difuminarse.

Así, Thompson afirma (1908, 24-25) que, más allá de interferencias diacrónicas ${ }^{18}$ en su evolución desde época clásica, en el NT ambos verbos mantienen una clara diferencia de significado: $\mu \varepsilon \tau \alpha \nu o \varepsilon ́ \omega$ expresa siempre un cambio de propósito, en un contexto moral, del mal al bien, un cambio interno que se refleja en una conducta externa, pero que nunca se identifica con - y a veces se distingue claramente de - la pena o el arrepentimiento, sentido este último que le corresponde inherentemente a

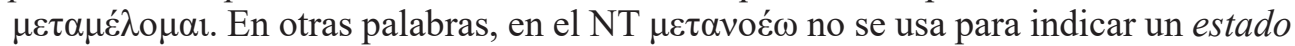
emocional, como $\mu \varepsilon \tau \alpha \mu \varepsilon ́ \lambda o \mu \alpha 1$, sino para expresar una acción volitiva y, además, moral: el cambio de propósito es siempre del mal al bien (Thompson 1908, 28). En el mismo sentido se expresa Laubach $(2012,333)$ : mientras que $\mu \varepsilon \tau \alpha \mu \varepsilon ́ \lambda o \mu \alpha \iota$ «designa más bien la experiencia del arrepentimiento» por el desliz, la falta, la culpa o el pecado, $\mu \varepsilon \tau \alpha v o \varepsilon ́ \omega$ «significa el apartamiento consciente del pecado, el cambio de la mentalidad» (la cursiva es nuestra).

16 Esta construcción, en la que el dativo se comporta como un 'semisujeto', está limitada en griego antiguo a unos

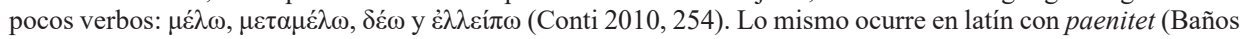
2003) y otros verbos de sentimiento (miseret, puder, piget, taedet), que se construyen con el Experimentador en acusativo y la causa del sentimiento en genitivo ( $c f$. infra. $\S 5.2$ ).

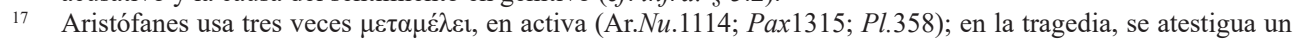

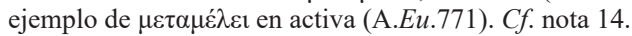

18 Thompson $(1908,14)$ hace ver que, hasta el s. I d.C., en escritores postaristotélicos no judíos $\mu \varepsilon \tau \alpha v o \varepsilon ́ \omega$ no se limita al uso clásico de 'cambio de opinión' como una acción puramente intelectual, sino que expresa también la voluntad de arrepentimiento por una acción anterior que se considera inconveniente o moralmente mala, una

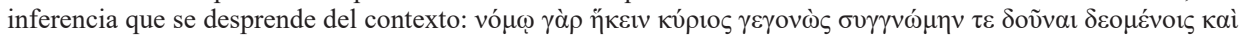

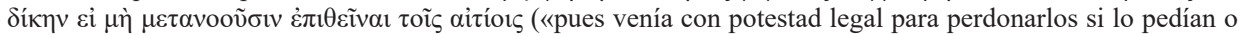
para castigar a los culpables si no se arrepentían», Plu.Cam.29.4). También entre los escritores judíos, $\mu \varepsilon \tau \alpha v o \varepsilon ́ \omega$, aunque mantiene el significado de 'cambio de opinión', en muchos ejemplos pasaría a significar 'arrepentirse'

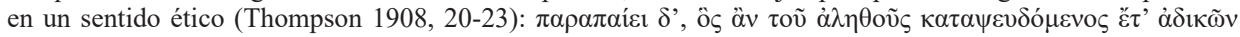

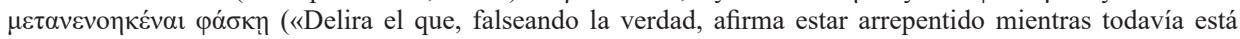
pecando», $\mathrm{Ph} .3 .17 .160$ ). Todo parece indicar, pues, que $\mu \varepsilon \tau \alpha v o \varepsilon ́ \omega$, que, en principio, expresa una acción inte-

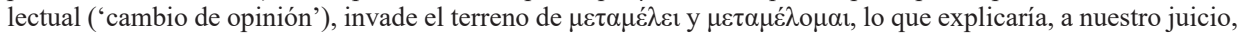
la disminución de estos últimos en época helenística en beneficio del primero. De hecho, Filón de Alejandría, como muestran los datos del Cuadro (2), ya solo usa $\mu \varepsilon \tau \alpha v o \varepsilon ́ \omega$. 


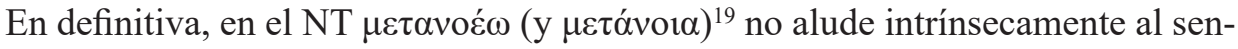

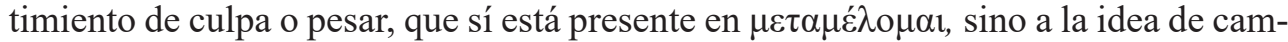
bio, reflexión, transformación y, finalmente, conversión ( $c f$. también BDAG s.v. $)^{20}$.

3.3. Esta diferencia de significado entre $\mu \varepsilon \tau \alpha v o \varepsilon ́ \omega$ y $\mu \varepsilon \tau \alpha \mu \varepsilon^{\prime} \lambda{ }_{0} \mu \alpha$ en el NT tiene, además, reflejo en su comportamiento sintáctico, un aspecto sobre el que no se ha llamado suficientemente la atención: con $\mu \varepsilon \tau \alpha v o \varepsilon ́(\omega$ es frecuente el empleo de formas de imperativo ( $\mu \varepsilon \tau \alpha v o \varepsilon i \tau \varepsilon, \mu \varepsilon \tau \alpha v o \eta ́ \sigma \alpha \tau \varepsilon, \mu \varepsilon \tau \alpha v o ́ \eta \sigma o v)$ — como en los ejemplos ya citados de (3) y (4) - completivas de modalidad deóntica — como en la final-completiva con îva y subjuntivo de (12a) o la completiva de infinitivo de (12b)-, o períodos condicionales que denotan, en su conjunto, una fuerza ilocutiva directiva - del tipo "si no os enmendáis, todos pereceréis" (es decir, "debéis enmendaros"), como en (13) - Muy ilustrativo a este

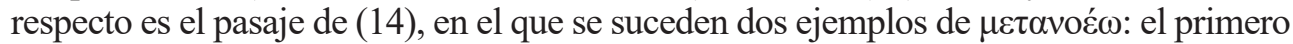
en una subordinada final, por naturaleza controlada (Crespo et al. 2003, 417), seguido de una completiva de infinitivo ( $\mu \varepsilon \tau \alpha v o \tilde{\sigma} \sigma \alpha)$ en dependencia de un verbo volitivo (ở $\theta \varepsilon \dot{\lambda} \varepsilon 1)$, como prueba de que $\mu \varepsilon \tau \alpha v o \varepsilon ́ \omega$ expresa una acción intencionada:

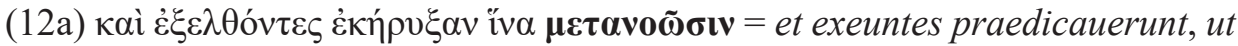
paenitentiam agerent («Ellos se marcharon y se pusieron a predicar que se enmendaran», Eu.Marc.6.12).

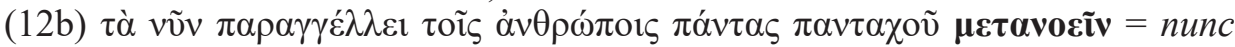
annuntiat hominibus, ut omnes ubique paenitentiam agant («[Dios] manda ahora a todos los hombres, en todas partes, que se enmienden», Act.Ap.17.30).

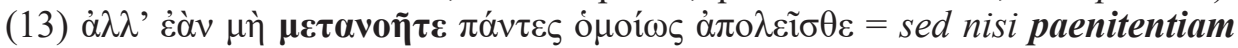
egeritis, omnes similiter peribitis ( $\ll y$, si no os enmendáis, todos vosotros pereceréis también», Eu.Luc.13.3).

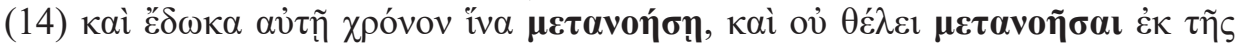

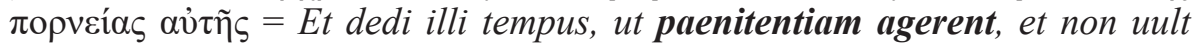
paeniteri a fornicatione sua («Le di tiempo para enmendarse pero no quiere enmendarse de su fornicación», Apoc.2.21).

Este tipo de contextos implica que dicho verbo conceptualiza una situación controlada en la que el sujeto desempeña la función semántica de Agente y tiene, por tanto, la capacidad de realizar o no la acción expresada por el verbo. Al menos 18 de los 29 ejemplos de $\mu \varepsilon \tau \alpha v o \varepsilon ́ \omega$ del NT traducidos por paenitentiam agere aparecen en este tipo de contextos: denotan, por tanto, una situación activa, controlada por un sujeto Agente ${ }^{21}$, congruente con el hecho de que, desde el punto de vista de su signi-

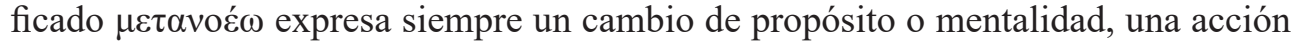
volitiva e intencionada en la que está implicado activamente el sujeto.

19 A diferencia de paenitentia, y con un uso menos frecuente en el NT (22 ejemplos), $\mu \varepsilon \tau \alpha ́ v o t \alpha$ no configura en griego ninguna CVS.

20 La frecuencia de $\mu \varepsilon \tau \alpha v o \varepsilon ́ \omega$ en el NT tiene que ver, sin duda, con la centralidad de su significado en el mensaje cristiano. Jesús predicó la necesidad (Eu.Matt.4.17) que tenían los judíos de enmendarse, de cambio y conversión, y pidió reiteradamente a sus discípulos que trasladaran ese mensaje a judíos y gentiles: Eu.Luc.24.47, Act. Ap.2.38, 17.30 .

${ }_{21}$ Ejemplos de imperativos: Eu.Matt.3.2, 4:17; Eu.Marc.1.15; Act.Ap.2.38, 3.19, 8.22; Apoc.2.5, 2.16, 3.3 , 3.19. Completivas deónticas o finales controladas: Eu.Matt.11.20; Eu.Marc.6.12; Act.Ap.17.30, 26.20; Apoc.2.21. Períodos condicionales con inferencia impresiva, similares a (13): Eu.Luc.13.3, 13.5; Apoc.2.5, 2.22. 
En cambio, $\mu \varepsilon \tau \alpha \mu \dot{\lambda} \lambda o \mu \alpha$ en el NT nunca aparece en imperativo o en contextos similares a los ejemplos de (12)-(14), ya que expresa un sentimiento, un estado emocional, por definición menos controlado: prueba de ello es que, como en tantos otros verbos de sentimiento, la persona afectada (que, en términos de funciones semánticas, es un Experimentador más que un Agente) ${ }^{22}$ o no se codifica siquiera como sujeto sintáctico (construcción impersonal con $\mu \varepsilon \tau \alpha \mu \varepsilon ́ \lambda \varepsilon ı$ ), o, en el caso de hacerlo (construcción personal), el verbo se construye obligatoriamente en voz media (diátesis anticausativa).

En definitiva, tanto la morfología de $\mu \varepsilon \tau \alpha \nu o \varepsilon ́ \omega$ y $\mu \varepsilon \tau \alpha \mu \varepsilon ́ \lambda o \mu \alpha$, como su comportamiento sintáctico son congruentes con las diferencias de significado entre ellos, unas diferencias que, como vamos a ver a continuación, tienen su reflejo también en la traducción latina de la Vulgata: en la elección de las distintas CVS con paenitentia $(\S 4)$ y en el empleo de la construcción sintáctica (personal o impersonal) del verbo paenitere $(\S 5)$.

3.4. Pero, antes de comentar la traducción latina de la Vulgata, no está de más una breve reflexión sobre la traducción misma al español de $\mu \varepsilon \tau \alpha v o \varepsilon ́ \omega$ y $\mu \varepsilon \tau \alpha \mu \varepsilon ́ \lambda o \mu \alpha$.

En el Diccionario de la Lengua Española de la RAE ( $23^{\mathrm{a}} \mathrm{ed}$.), el verbo arrepentirse presenta dos acepciones: «1. prnl. Dicho de una persona: Sentir pesar por haber hecho o haber dejado de hacer algo. 2. prnl. Cambiar de opinión o no ser consecuente con un compromiso». El verbo castellano, por tanto, recoge en la primera acepción

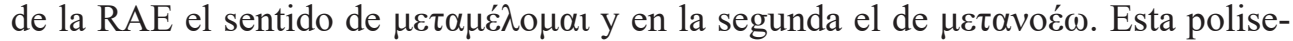
mia de arrepentirse justifica el que los traductores acudan a este verbo en español

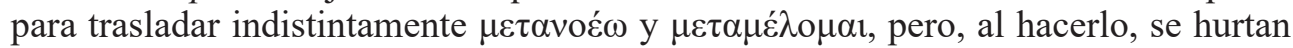
al lector las diferencias entre los dos verbos griegos, que quedan relegadas a la intepretación del contexto.

La traducción de Cantera-Iglesias (2009) es una buena muestra de esta opción: todos los ejemplos del NT citados hasta ahora de $\mu \varepsilon \tau \alpha v o \varepsilon ́ \omega ~ o ~ \mu \varepsilon \tau \alpha \mu \varepsilon ́ \lambda o \mu \alpha \iota$ se traducen indistintamente por «arrepentirse». En el polo opuesto está la traducción de MateosAlonso Schökel (1987), que es la que hemos utilizado por ser la que mejor vierte al castellano la diferencia entre los dos verbos griegos: mientras que $\mu \varepsilon \tau \alpha v o \varepsilon ́ \omega$, en (3)-(4) o (12)-(14), se traduce por «enmendarse», trasladando así el valor originario

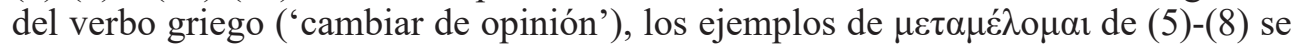
vierten, en cambio, por «sentir remordimiento», es decir, como un verbo de sentimiento.

Entre estos dos polos, con mayor o menor coherencia, discurre el resto de traducciones consultadas ${ }^{23}$.

22 Desde el punto de vista de la clasificación semántica de los predicados, mientras que $\mu \varepsilon \tau \alpha v o \varepsilon ́ \omega$ denota una Acción, que supone «el control de un agente e implica un cambio en alguno de los participantes», $\mu \varepsilon \tau \alpha \mu \varepsilon \dot{\lambda} о \mu \alpha$ l expresaría un proceso, es decir, «situaciones dinámicas no controladas por un agente» (Crespo-Conti-Maquieira 2003, 236-237). De ahí que sólo $\mu \varepsilon \tau \alpha v o \varepsilon ́ \omega$ documente en el NT imperativos y empleos impresivos (§ 3.3). En términos de Funciones Semánticas, el sujeto de $\mu \varepsilon \tau \alpha v o \varepsilon ́ \omega$ es Agente, mientras que el de $\mu \varepsilon \tau \alpha \mu \varepsilon ́ \lambda o \mu \alpha$ es un Experimentador (id. 2003, 106-108).

23 Así, en la de la Conferencia Episcopal Española (2010), los ejemplos de $\mu \varepsilon \tau \alpha v o \varepsilon ́ \omega$ de (3)-(4) y (12)-(14) se

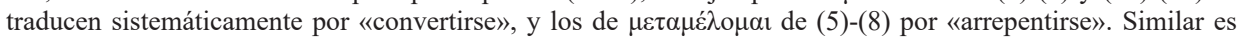
la forma de traducción en La Biblia dirigida por S. De Ausejo de la editorial Herder (2003) o de la Biblia interconfesional, auspiciada por la Sociedad Bíblica de España (2008), para el caso de $\mu \varepsilon \tau \alpha v o \varepsilon ́ \omega$ (siempre «convertirse»), mientras que $\mu \varepsilon \tau \alpha \mu \varepsilon ́ \lambda o \mu \alpha$ se vierte con más variedad: «no me pesa» (3), «asaltado por los remordimientos» (7) o «se arrepintió» (8), en La Biblia de Herder; «no me pesa» (3), «no cambiasteis de actitud» 


\section{La traducción latina mediante colocaciones con paenitentia}

Con estas consideraciones previas, y teniendo en cuenta las diferencias de significado entre $\mu \varepsilon \tau \alpha v o \varepsilon ́ \omega$ y $\mu \varepsilon \tau \alpha \mu \varepsilon ́ \lambda o \mu \alpha \imath$ en el NT, es hora de profundizar en la versión latina de la Vulgata y comprobar hasta qué punto Jerónimo en los evangelios traduce libremente los dos verbos griegos, como parecían mostrar los ejemplos de (3)-(8), o más bien intenta reflejar esas diferencias mediante la elección de CVS distintas o del verbo simple paenitere.

Vamos a analizar para ello, en primer lugar, las distintas CVS (paenitentiam agere, paenitentiam habere, paenitentiā ductus y paenitentiā motus), ya que esta

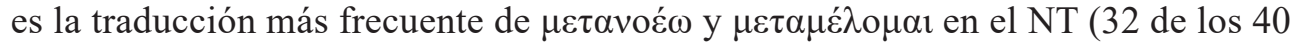
ejemplos).

4.1. De estas cuatro colocaciones, tal como mostraban los datos del Cuadro (1), paenitentiam agere no solo es, con diferencia, la más habitual (29 de esos 32 ejemplos), sino que, además, traduce siempre ejemplos de $\mu \varepsilon \tau \alpha v o \varepsilon ́ \omega$, sin que parezca haber diferencias de empleo entre los evangelios (13 ejemplos $)^{24}$ y el resto de libros del Nuevo Testamento (16 ejemplos) ${ }^{25}$ :

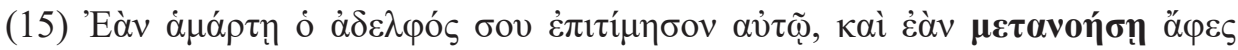

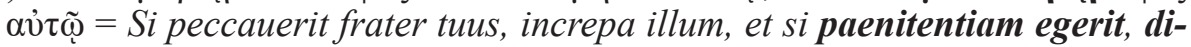
mitte illi («Si tu hermano te ofende, repréndelo; y, si se arrepiente, perdónalo», Eu.Luc.17.3).

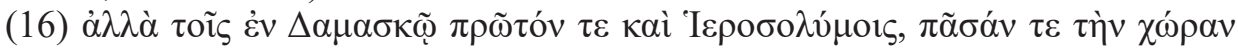

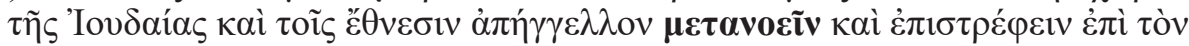
$\theta \varepsilon o ́ v=$ sed his, qui sunt Damasci primum et Hierosolymis, et in omnem regionem Iudaeae et gentibus annuntiabam, ut paenitentiam agerent et converterentur ad Deum ( $\mathrm{Al}$ contrario, primero a los de Damasco y a los de la ciudad de Jerusalén, luego a todo el país judío y a los paganos, les he ido predicando que se arrepientan y se conviertan a Dios», Act.Ap.26.20).

Estamos, pues, ante una primera regularidad en la traducción de la Vulgata y ante un ejemplo paradigmático en el NT de la diferencia en la frecuencia de empleo de las colocaciones en griego y en latín (§ 1.2-1.3): $\mu \varepsilon \tau \alpha v o \varepsilon ́ \omega$ es traducido sistemáticamente (en 29 de los 34 ejemplos) por una CVS a pesar de existir en latín un verbo, paenitere, que permitiría, a priori, una traducción más literal (verbum e verbo).

4.2. Pero, además, desde la perspectiva interna del latín, esta prevalencia de la CVS sobre el verbo simple en la Vulgata supone una diferencia importante respecto al empleo de paenitentiam agere y paenitere en latín clásico: aparecen más ejemplos de paenitentiam agere en el NT que en toda la literatura latina de Plauto a Aulo Gelio ${ }^{26}$.

(6) o «se llenó de remordimiento» (7), en la Biblia interconfesional. La traducción de O’Callaghan (1996) es menos sistemática.

$24 \quad$ Eu.Matt.3.2, 4.17. 11.20, 11.21, 12:41; Eu.Marc.6.12; Eu.Luc.11.32, 13.3, 13.5, 15.7, 15.10, 16.30, 17.3.

25 Act.Ap.2.38, 8.22, 17.30, 26.20; 2Ep.Cor.12.21; Apoc.2.5, 2.5, 2.16, 2.21, 2.22, 3.3, 3.19, 9.20, 9.21, 16.9, 16.11.

26 Hemos realizado la búsqueda, mediante el programa Diogenes, en el corpus de autores recogido en el CD-ROM del Instituto de Humanidades Packard (PHI \# 5.3). 
En efecto, esta CVS no se documenta ni en latín arcaico (Plauto y Terencio) ni en prosa clásica (César, Cicerón, Nepote, Salustio o Livio), ni, por razones prosódicas, en toda la poesía dactílica. En realidad, de Plauto a Aulo Gelio, apenas hemos encontrado una docena ${ }^{27}$ de ejemplos de paenitentiam agere: salvo Valerio Máximo (4 ejemplos) el resto de autores emplea esta CVS de forma esporádica, justo lo contrario que el verbo paenitere ${ }^{28}$.

(17a) respondit utrum eorum fecisset acturum paenitentiam («le respondió que hiciese lo que hiciese acabaría arrepintiéndose», Val. Max.7.2ext.1).

(17b) etiam si incolumis fuisset, paenitentiam salutis acturus («aunque se hubiese salvado, iba a sentir remordimiento por seguir con vida», Sen.dial.6.20.4).

(17c) paenitentiam agere sermonis mei coepi («empecé a lamentar mis palabras», Petron.132.12).

(17d) Neque illius' inquit 'sermonis mei paenitentiam ago... («Y no me arrepiento -dijo- de aquellas palabras...», Tac.dial.15.2).

Así las cosas, el empleo de paenitentiam agere en el NT no hace sino continuar una colocación ya presente en latín postclásico, pero cuyo uso se ha generalizado en latín tardío hasta desplazar al verbo paenitere (§ 5). La fidelidad a la consuetudo, al uso habitual de la lengua latina del s. IV, juega, como es sabido (Meershoek 1966, 244), un papel fundamental en la traducción de Jerónimo, diferenciándose así de las versiones previas de la Vetus Latina, más preocupadas por una literalidad extrema (verbum e verbo ${ }^{29}$.

4.3. En cuanto al otro verbo griego, $\mu \varepsilon \tau \alpha \mu \varepsilon ́ \lambda o \mu \alpha 1$, que en el NT expresa la idea de 'sentir arrepentimiento', su empleo, tal como mostraban los datos del Cuadro (1), es mucho menos frecuente que $\mu \varepsilon \tau \alpha v o \varepsilon ́ \omega$ (6 ejemplos frente a 34), y, en congruencia con su diferencia de significado, se traduce al latín, además, de forma diferente: mientras que $\mu \varepsilon \tau \alpha v o \varepsilon ́ \omega$, que expresa una acción controlada, volitiva e intencional (§ 3.3), se vierte sistemáticamente por una colocación 'activa' como paenitentiam agere, $\mu \varepsilon \tau \alpha \mu \varepsilon ́ \lambda \mathrm{o} \mu \alpha$, en cambio, al expresar un proceso emocional, un sentimiento, se traduce por tres colocaciones distintas, todas ellas en el evangelio de Mateo: paenitentiam habere (18), paenitentiā ductus (19) y paenitentiā motus (20):

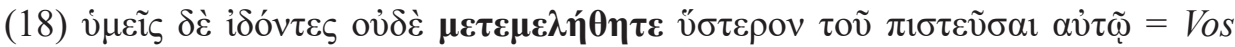
autem uidentes nec paenitentiam habuistis postea, ut crederetis ei («Pero vo-

27 La relación completa de los ejemplos de paenitentiam agere es la siguiente: Val.Max.1.5ext..2, 3.4.2, 7.2ext..1, 7.2ext.11; Sen.suas.6.11, 7.10; Curt.8.6.23; Sen.dial. 6.20.4; Petron.132.12; Quint.inst.9.3.12; Ps.Quint.decl. min.336.4; Plin.epist.7.10.3; Tac.dial.15.2.

28 En una búsqueda paralela en el corpus de PHI, el número de ejemplos de paenitere en algunos autores significativos es el siguiente: Plauto (15 ejs.), Terencio (4), César (2), Cicerón (107), Virgilio (3), Horacio (4), Livio (63), Ovidio (26), Séneca el Viejo (10), Apuleyo (14), Frontón (5) o Aulo Gelio (15). Sólo en Valerio Máximo la CVS (4 ejemplos) se emplea con mayor frecuencia que el verbo simple (2 ejemplos).

29 En efecto, en los evangelios, tanto en las versiones de la Vetus Afra como de la Itala, en varios de los pasajes recogidos en nota $24, \mu \varepsilon \tau \alpha v o \varepsilon ́ \omega$ no se traduce por paenitentiam agere, sino por paenitere: EuMatt.11.21 (VL Afr.: peniterent), 12.41 (VL Afr.: penituerunt), Eu.Luc.13.5 (VL Ital.: penitueritis). Particularmente llamativo es Eu.Luc.11.32, porque en vez de paenitentiam egerunt de la Vulgata y de la mayoría de manuscritos de la Itala (salvo $c$ : paenituit eos), la Afra presenta la lectura paenitentiam gesserunt, lo que muestra en último término la confusión entre verbos soporte próximos (facio / ago / gero). 
sotros, ni aún después de aquello habéis sentido remordimiento ni le habéis creído», Eu.Matt.21.32).

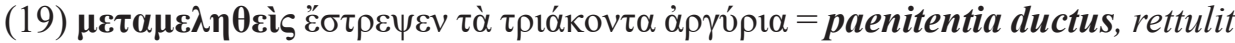
triginta argenteos («[Judas] sintió remordimientos y devolvió las treinta monedas de plata», Eu.Matt.27.3).

(20) («pero después sintió remordimiento y fue», Eu.Matth.21.29).

Obsérvese, en primer lugar, que los tres ejemplos de $\mu \varepsilon \tau \alpha \mu \varepsilon ́ \lambda o \mu \alpha \iota$ en Mateo aparecen en el tema de aoristo, con el morfema $-\theta \eta-{ }^{30}$ propio de un aoristo intransitivo (impropiamente llamado 'pasivo') y habitual con verbos deponentes como $\beta$ ov́

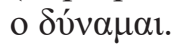

En el primero de ellos (18), con el verbo griego en forma personal ( $\mu \varepsilon \tau \varepsilon \mu \varepsilon \lambda \eta \dot{\eta} \theta \eta \tau \varepsilon)$, Jerónimo emplea habeo como verbo soporte de paenitentiam ${ }^{31}$, porque es un verbo que configura habitualmente colocaciones con predicados que expresan estados y procesos poco controlados ${ }^{32}$ :

(21) summum bonum inmortale est, nescit exire, nec satietatem habet nec paenitentiam («El sumo bien es inmortal, no puede abandonar, ni se sacia ni siente pesar», Sen.dial.7.7.4).

La elección, por tanto, de la CVS paenitentiam habere, además de excepcional ${ }^{33}$, está semánticamente justificada y es mucho más transparente que paenitentiam agere para traducir un verbo de sentimiento como $\mu \varepsilon \tau \alpha \mu \varepsilon ́ \lambda o \mu \alpha \imath$ ('tener / sentir remordimiento').

4.4. Los ejemplos (19) y (20) tienen, a su vez, en común que el verbo griego es una forma de participio de aoristo con el morfema intransitivo - $\theta \varepsilon i ́ \varsigma$ ('pasivo'): $\mu \varepsilon \tau \alpha \mu \varepsilon \lambda \eta \theta \varepsilon i ́ c$. En tales casos, puesto que no existe en latín un participio paralelo de paenitet $^{34}$ ni cabe la pasiva morfológica de paenitentiam habeo (*paenitentia

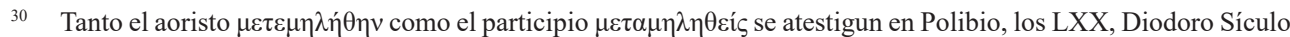
y Plutarco. Esta misma formación aparece en futuro, como es frecuente en el griego helenístico en los verbos deponentes que, en ático, tenían un aoristo morfológicamente pasivo, pero un futuro medio: en el NT hay un único

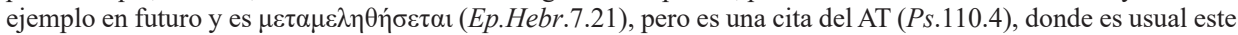

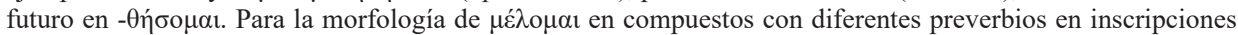
áticas y jonias desde s. IV a.C. $c f$. BDF 1961, 53; en papiros, $c f$. Mayser I 2, 115, 158, 159; I 3, 226; II 2, 213.

31 Aunque Jülicher et al. $(1972,153)$ reconstruyen también la lectura paenitentiam habuistis en su edición de la Vetus Latina, algunos manuscritos de Itala presentan paenitentiam egistis $(f h q)$ o paenituistis $(d)$.

32 Un valor que resulta evidente cuando, con un mismo sustantivo, se contrapone habere a verbos 'activos' como facere, agere o gerere: finem alicuius facit («pone fin a algo») / aliquid finem habet («algo tiene fin»).

33 Hay con todo dos pasajes de Lucas con $\mu \varepsilon \tau \alpha \nu$ oś $\omega$ en los que las ediciones de la Vulgata dudan entre agere y habere como verbo soporte, por falta de coincidencia entre los manuscritos. Frente a la edición de Nestle-Aland que estamos citando, en Eu.Luc.13.3 tanto Wordsworth-White como Weber-Gryson prefieren nisi paenitetiam habueritis, a pesar de que dos versículos después mantienen, en cambio, si paenitentiam non ageritis, tra-

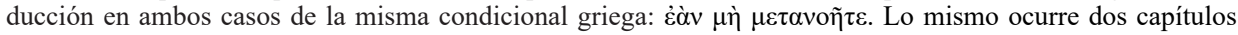

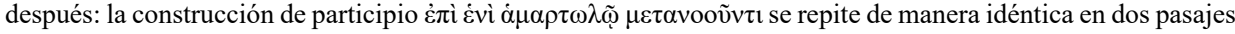
contiguos (Eu.Luc.15.7 y 15.10), pero, mientras que Nestle-Aland mantienen en ambos una misma traducción de la Vulgata (super uno peccatore paenitentiam agente), Wordsworth-White y Weber-Gryson prefieren en Eu.Luc. 15.7 paenitentiam habente.

34 Como verbo defectivo, paenitet carece de una forma de supino sobre la que configurar un participio en -tus, o un infinitivo de futuro tanto en activa (paeniturum) como en pasiva (*paenitum iri). A este respecto, resulta 
habita), el latín, como con otros verbos de sentimiento, genera colocaciones diatéticamente medio-pasivas, con el sustantivo verbal en ablativo complementando a participios de perfecto de verbos de movimiento (ductus, adductus, motus, actus).

En efecto, este tipo de colocaciones se documenta en el NT no sólo con paenitentia, sino también con otros sustantivos de sentimiento para traducir formas verbales griegas con el aoristo en $-\theta \eta v$. Así, una colocación similar, misericordia motus, en (22), es traducción sistemática en el evangelio de Lucas de la forma verbal griega

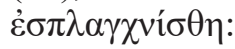

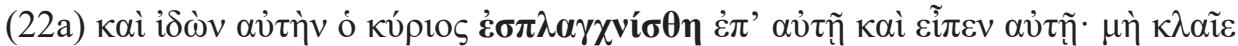
= Quam cum uidisset Dominus, misericordia motus super ea dixit illi: «Noli flere!» («Al verla el Señor, se conmovió y le dijo: — No llores», Eu.Luc.7.13).

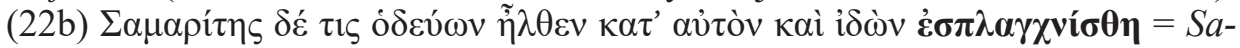
maritanus autem quidam iter faciens, uenit secus eum et uidens eum misericordia motus est («Pero un samaritano que iba de viaje llegó adonde estaba el hombre y, al verlo, se conmovió», Eu.Luc.10.33).

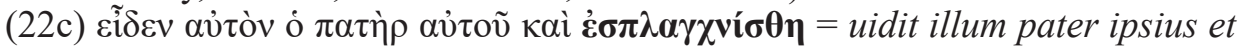
misericordia motus est («lo vió su padre y se conmovió», Eu.Luc.15.20).

También paenitentia, tanto en la literatura latina anterior (23), como en el propio latín bíblico (24), documenta este tipo de colocación (en ablativo + participio pasivo), lo que muestra en último término su grado de gramaticalización como expresión léxica de una diátesis pasiva. Así, por ejemplo, Gayo, jurista latino de mediados del s. II d.C. emplea ya la colocación paenitentiā actus (23), colocación que aparece también en el libro de la Sabiduría (24a) para traducir de nuevo un participio de aoristo con el morfema $-\theta \eta$ - como $\mu \varepsilon \tau \alpha \mu \varepsilon \lambda \eta \theta \varepsilon ́ v \tau \varepsilon \varsigma$. En (24b) esa misma colocación traduce un verbo de sentimiento $(\pi \alpha \rho \varepsilon \kappa \lambda \eta \dot{\theta \eta} \sigma \alpha v)$ con un sentido similar a $\mu \varepsilon \tau \alpha \mu \varepsilon ́ \lambda o \mu \alpha$ ('sentir lástima'):

(23) itaque licet ante diem cretionis constituerit hereditatem non adire, tamen paenitentia actus superante die cretionis cernendo heres esse potest («Por lo tanto, aunque haya decidido no hacerse cargo de la herencia antes del día de su aceptación formal, sin embargo, si cambia de parecer, puede convertirse en heredero...», Gaius.inst.2.168).

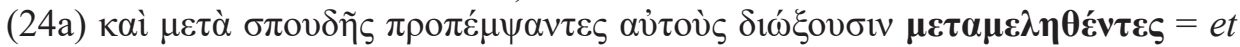
cum magna sollicitudine promisissent illos, consequebantur illos, paenitentia acti («tras dejarlos marchar y urgirlos con prisas, cambiarían de parecer y saldrían a perseguirlos», Sap.19.2).

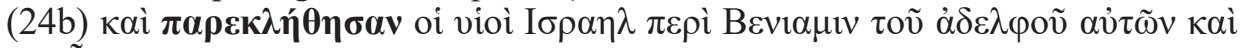
घĩ $\pi \alpha v$... = ductique paenitentia filii Israël super fratre suo Benjamin, coeperunt dicere («Los hijos de Israel sentían lástima de su hermano Benjamín y repetían...», Id.21.6).

muy ilustrativo el pasaje de Quintiliano en el que critica el empleo por parte de Salustio de la forma arcaizante de infinitivo paeniturum cuando la CVS paenitentiam acturum podía suplir las carencias morfológicas de paenitet: unde eo usque processum est ut 'non paeniturum' pro non acturo paenitentiam ... auctor dixerit (Quint. inst.9.3.12), Para el comentario de este pasaje, $c f$. Baños (2017). 


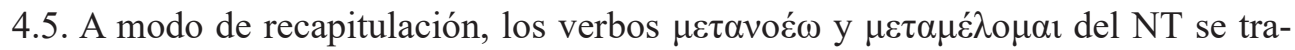
ducen en el latín de la Vulgata mediante colocaciones distintas, en congruencia con su diferencia de significado. Mientras que $\mu \varepsilon \tau \alpha v o \varepsilon ́ \omega$ ('cambiar de parecer'), que expresa una acción intencional, controlada por un Agente, se vierte sistemáticamente mediante la construcción con verbo soporte semánticamente activa como paenitentiam ago, $\mu \varepsilon \tau \alpha \mu \varepsilon \dot{\lambda}{ }_{0} \mu \alpha 1$, que expresa un sentimiento ('tener/ sentir remordimiento'), aparece siempre en voz media (diátesis anticausativa), denotando así una situación menos controlada, lo que justifica la elección de la CVS paenitentiam habeo, o de colocaciones como paenitentiā ductus / motus, que se emplean sistemáticamente, en latín postclásico y tardío, como expresión léxica de la diátesis pasiva con sustantivos que expresan sentimientos.

La elección, en suma, de las distintas colocaciones latinas para la traducción de

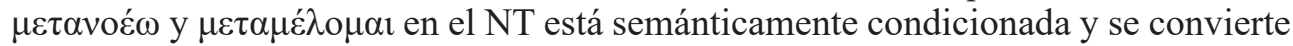
así en un procedimiento para marcar, de manera explícita, las diferencias de significado y de diátesis de los verbos originales griegos.

\section{La traducción mediante el verbo paeniteo / paenitet}

Quedan por analizar los ejemplos en que dichos verbos griegos se traducen en latín, no mediante una colocación, sino mediante el verbo latino paenitere. Ello ocurre en

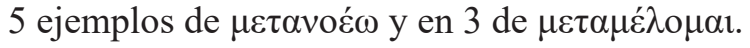

5.1. A priori, la traducción por paenitere, más literal (verbum e verbo), se podría considerar también más 'clásica', en la medida en que es este verbo y no las CVS el que se emplea en César, Cicerón y Livio. Ahora bien, a la luz de los datos comentados, el empleo de colocaciones ya documentadas en latín postclásico, además de resultar más explícitas a la hora de marcar las diferencias semánticas entre los dos verbos griegos, refleja mejor la consuetudo del latín del siglo IV. Sobre todo, en el caso de paenitentiam agere, que, como hemos visto ( $\$ 4.2$ ), ha desplazado ya al verbo simple (paenitere) como expresión del predicado 'arrepentirse'.

Queda, sin embago, por explicar las razones por las que paenitere, aunque menos empleado en la Vulgata que las colocaciones verbo-nominales con paenitentia, se

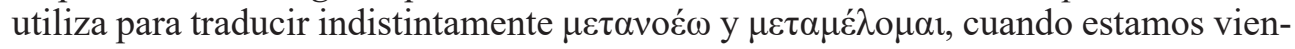
do que los dos verbos griegos tienen significados distintos en el NT.

5.2. Para responder a esta cuestión, es necesaria una puntualización previa importante. Salvo un ejemplo puntual de Pacuvio (trag.31), el verbo paenitere aparece siempre, de Plauto a Aulo Gelio, en construcción impersonal, es decir, con la persona que experimenta el sentimiento en acusativo (eos) y la causa del sentimiento en genitivo (peccatorum):

(25) eos quis secus ac decuit uixerunt, peccatorum suorum ... paenitet ( LLos que han vivido contra el decoro... se arrepienten de sus faltas», Cic.div.1.63).

Pero, en un proceso similar, en parte, al de $\mu \varepsilon \tau \alpha \mu \varepsilon ́ \lambda o \mu \alpha \iota$ en griego (§ 3.1), paenitere fue configurándose progresivamente como personal, es decir, con el Experimen- 
tador como sujeto sintáctico, un proceso gradual que no se gramaticaliza plenamente en latín hasta el siglo III d.C. (Baños 2003, 74).

Otros verbos impersonales de sentimiento, en cambio, documentan las dos construcciones (impersonal y personal) desde época arcaica. Es el caso miserere ('compadecerse'), cuya construcción impersonal (miseret) convive con una construcción personal doble, según que el segundo argumento se exprese en genitivo (familiae misereor) o en acusativo (casum miseror). Pues bien, «la razón fundamental que justifica el que estas estructuras convivan durante tanto tiempo es que las construcciones personales muestran un mayor grado de control e intencionalidad que la impersonal» (Tur 2013, 250, la cursiva es nuestra).

5.3. En el caso de paenitere es precisamente en época tardía (s. IV d.C.) cuando coexisten ambas construcciones, por lo que cabría esperar una diferencia de la misma naturaleza que miseret vs. miser(e)or. De ser así, dicha diferencia podría reflejarse

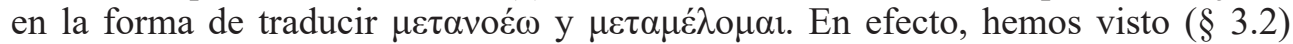
que $\mu \varepsilon \tau \alpha v o \varepsilon ́ \omega$ expresa una Acción, con un sujeto Agente, que, como tal, presenta los rasgos de control y intencionalidad, mientras que con $\mu \varepsilon \tau \alpha \mu \varepsilon ́ \lambda o \mu \alpha 1$ (siempre en voz media anticausativa) el sujeto se conceptualiza como un Experimentador con un grado de control menor sobre el predicado de sentimiento.

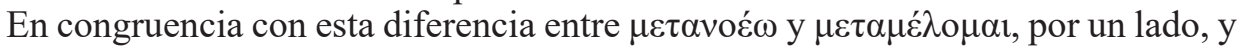
con la distribución entre construcción personal e impersonal de los verbos latinos de sentimiento, por otro, sería esperable que $\mu \varepsilon \tau \alpha v o \varepsilon ́ \omega$ se tradujera en latín con el verbo

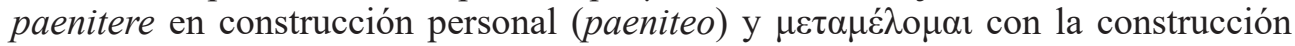
impersonal (me paenitet).

Y así es de manera casi perfecta: en los tres ejemplos de $\mu \varepsilon \tau \alpha \mu \varepsilon ́ \lambda o \mu \alpha \imath$ que se traducen por paenitere y no por una colocación en el $\mathrm{NT}^{35}$, el verbo latino aparece siempre en construcción impersonal: me paenitet en (26), aunque en la segunda oración (paeniteret), por contigüidad, no se explicita el acusativo de persona, y paenitebit me en (27), que es en realidad una cita del Antiguo Testamento (Ps.110.4):

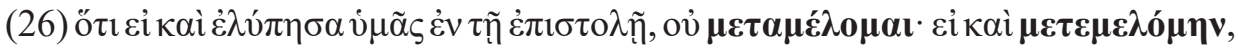

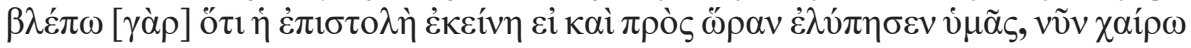
= Quoniam etsi contristaui uos in epistula, non me paenitet; etsi paeniteret -uideo quod epistola illa, etsi ad horam, uos contristauit-nunc gaudeo («Por eso, aunque os causé pena con mi carta, no lo siento; antes lo sentía, viendo que aquella carta os dolió, aunque fue por poco tiempo», 2Ep.Cor.7.8-9).

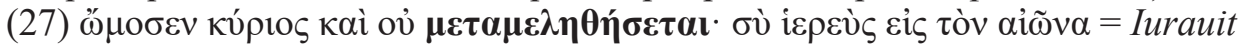
Dominus, et non paenitebit eum: tu es sacerdos in aeternum («El Señor lo ha jurado y no se arrepentirá: Tú eres sacerdote perpetuo», Ep.Hebr.7.21).

35 La misma regularidad se da en el AT. De los 8 pasajes en los que $\mu \varepsilon \tau \alpha \mu \varepsilon ́ \lambda o \mu \alpha$ se traduce por paenitere, en 7 de ellos el verbo latino se construye en forma impersonal: Ex.13.17; 1Reg. 15.35; 1Ma.11.10; Ps.105.45, 109.4; Si.33.20; Ie.20.16. La única excepción es Si.32.24, en forma personal, como cuando traduce $\mu \varepsilon \tau \alpha v o \varepsilon ́ \omega$ (Si.17.20 y 48.16). No está de más recordar que Jerónimo no revisó la traducción antigua del libro del Eclesiástico (García de la Fuente 1990, 96). De haberlo hecho, es más que probable que hubiera mantenido la regularidad (construcción impersonal / personal) de paenitere como traducción, respectiva, de $\mu \varepsilon \tau \alpha \mu \varepsilon ́ \lambda o \mu \alpha$ y $\mu \varepsilon \tau \alpha v o \varepsilon ́ \omega$. 
5.4. En el caso de $\mu \varepsilon \tau \alpha v o \varepsilon ́ \omega$, en cambio, sólo en uno (32) de los cinco ejemplos ${ }^{36}$ el verbo latino aparece en construcción impersonal, mientras que el resto - (28) a (31) - presenta una construcción personal con el sujeto en nominativo:

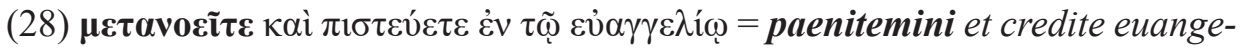
lio («Enmendaos y tened fe en esta buena noticia», Eu.Marc.1.15).

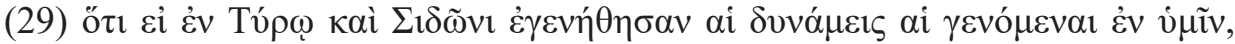

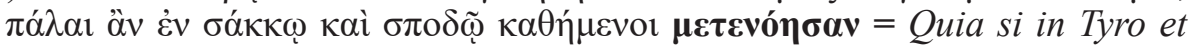
Sidone factae fuissent uirtutes, quae in uobis factae sunt, olim in cilicio et cinere sedentes paeniterent («Porque si en Tiro y en Sidón se hubieran hecho las potentes obras que en vosotras, hace tiempo que se habrían arrepentido vestidas de saco y sentadas en ceniza», Eu.Luc.10.13).

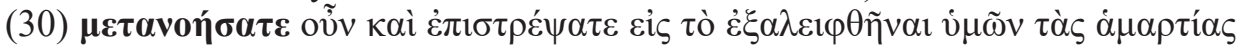
= paenitemini igitur et conuertimini, ut deleantur uestra peccata ( Por tanto, arrepentíos y convertíos para que se borren vuestros pecados», Act.Ap.3.19).

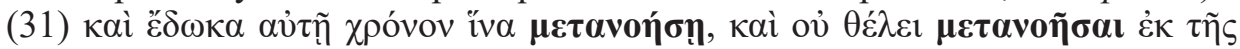

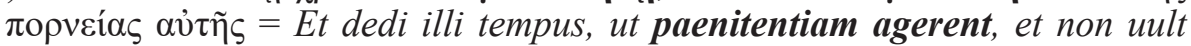
paeniteri a fornicatione sua («Le di tiempo para enmendarse pero no quiere enmendarse de su fornicación», Apoc.2.21).

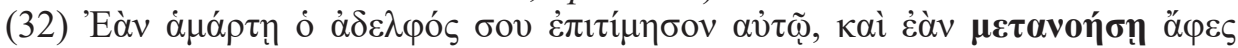

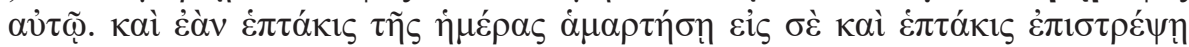

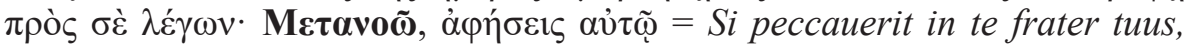
increpa illum, et si paenitentiam egerit, dimitte illi; et si septies in die peccauerit in te et septies conuersus fuerit ad te, dicens: "Paenitet me", dimitte illi («Si tu hermano te ofende, repréndelo; y, si se arrepiente, perdónalo. Si te ofende siete veces al día y vuelve siete veces a decirte: "Lo siento", lo perdonarás», (Eu.Luc.17.3-4).

Obsérvese, además, cómo la construcción personal de paenitere en latín está asociada a situaciones controladas y volitivas: en (28) y (30), el verbo aparece en imperativo, y en (31) forma parte de una oración final, por definición controlada.

5.5. Una última consideración. En el caso de $\mu \varepsilon \tau \alpha v o \varepsilon ́ \omega$, aunque tanto la CVS (siempre paenitentiam agere) como el verbo simple (construcción personal de paenitere) están semánticamente justificadas, ¿hay alguna diferencia entre ellos, más allá de la elección preferente de la CVS?

El ejemplo de (31) es, a este respecto, muy ilustrativo, ya que aparecen contiguas dos formas de $\mu \varepsilon \tau \alpha v o \varepsilon ́ \omega$ : la primera se vierte por paenitentiam ageret mientras que la segunda, a modo de variatio, para no repetir la misma forma en latín, se traduce con paenitere. Una contigüidad similar se da en (32): paenitentiam egerit $/$ paenitet me.

Este principio de variación es extensible a los otros ejemplos de la construcción personal. Así, la coordinación entre $\mu \varepsilon \tau \alpha v o \varepsilon ́ \omega$ y $\dot{\pi} \pi \_\tau \rho \varepsilon \dot{\varphi} \varphi \omega$ del ejemplo de (30) se vuelve a repetir, aunque no de forma contigua, en el texto griego de los Hechos de

36 En las versiones de la Vetus Latina, este ejemplo se presenta en forma personal, bien con el verbo conjugado como deponente (VL Ital.: paeniteor), bien mediante la CVS (VL Afr.: paenitentiam ago). 
los Apóstoles (33). Pues bien, la Vulgata evita repetir la misma traducción y alterna por ello entre el verbo simple de (30) y la CVS de (33):

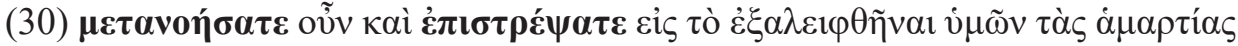
= Paenitemini igitur et conuertimini, ut deleantur uestra peccata («Por tanto, arrepentíos y convertíos para que se borren vuestros pecados», Act.Ap.3.19).

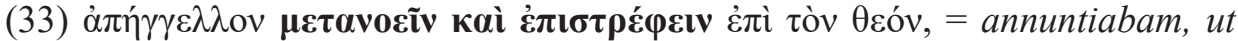
paenitentiam agerent et conuerterentur ad Deum («les he ido predicando que se arrepientan y se conviertan a Dios», Act.Ap.26.20).

Por último, los ejemplos de (28) y (29) ilustran otro tipo de variatio entre verbo simple y CVS muy habitual en la traducción de Jerónimo de los evangelios: en pasajes idénticos o paralelos, pero en evangelios distintos, a pesar de que el texto griego original es el mismo, la traducción latina varía de un evangelio a otro, cuando cabe la posibilidad de emplear indistintamente verbo simple y CVS. Los ejemplos paralelos de (28'), con la reproducción textual de las palabras de Juan el Bautista, y (29’) ilustran este principio:

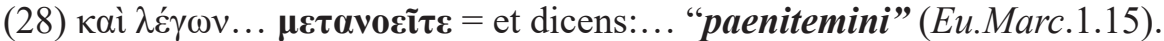

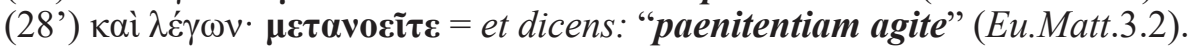

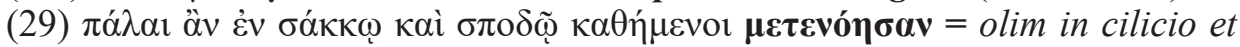
cinere sedentes paeniterent (Eu.Luc.10.13).

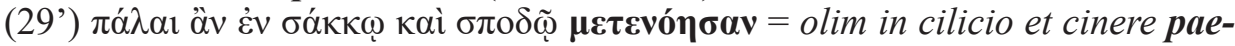
nitentiam egissent (Eu.Matt.11.21).

Aunque se podrían poner otros muchos ejemplos de variatio $^{37}$ allí donde la lengua latina le ofrece a Jerónimo la doble posibilidad de expresar un mismo predicado semántico como una CVS o como un verbo simple, baste recordar de nuevo el famoso pasaje del «no matarás, no cometerás adulterio, no robarás, no dirás falso testimonio»: mientras que en el texto griego de Mateo (34a), Marcos (34b) y Lucas (34c) las palabras textuales de Jesús no varían en su expresión (salvo cambios en el orden de los verbos o en su morfología), la traducción de Jerónimo es distinta en cada caso, de suerte que la misma forma verbal griega se traduce indistintamente en latín por un verbo simple o por una colocación. Así, povev́w por homicidium facere en (30a), pero por occidere en (30b-c), o $\kappa \lambda \dot{\varepsilon} \pi \tau \omega$ por furtum facere en (30a-c), pero por furari en (30b):

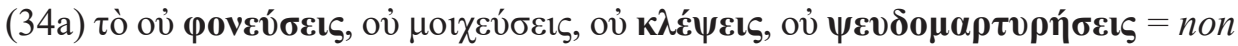
homicidium facies, non adulterabis, non facies furtum, non falsum testimonium dices Eu.Matt.19.18).

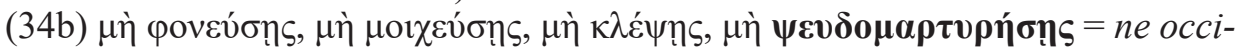
das, ne adulteres, ne fureris, ne falsum testimonium dixeris (Eu.Marc.10.19).

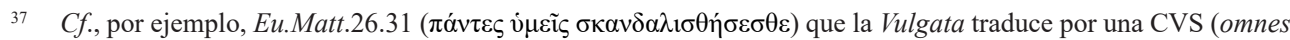

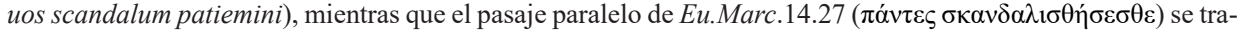
duce por el verbo simple (omnes scandalizabimini). Otra posibilidad de variatio es la elección de CVS distintas. Así, la misma colocación griega, expresada además de la misma forma en dos pasajes contiguos, $\sigma 0 \mu \beta$ ov́ $\lambda$ tóv $\tau \varepsilon$

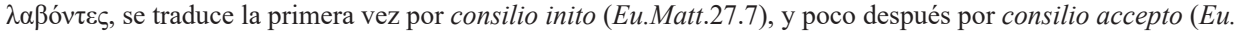
Matt.28.12). Para su análisis, cf. Jiménez López (2017). En la Vetus, en cambio, la búsqueda de una traducción literal hace que en ambos casos se traduzca por consilio accepto. 


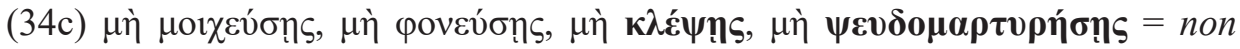
moechaberis, non occides, non furtum facies, non falsum testimonium dices (Eu.Luc.18.20).

\section{Conclusiones}

El latín, tanto en época clásica como tardía, emplea las construcciones con verbo soporte con mucha más frecuencia que la lengua griega, más rica en cambio en verbos compuestos y derivados. Este rasgo diferencial entre las dos lenguas tiene su reflejo en la traducción latina de la Vulgata del texto original griego del NT. A diferencia de la Vetus Latina, que en su afán de literalidad tiende a traducir verbum e verbo, la Vulgata (y de manera especial Jerónimo en los evangelios) traduce una forma verbal griega por una construcción con verbo soporte cuando estos predicados analíticos son la construcción más clásica en latín o la de uso más generalizado en la lengua del siglo IV d.C.

Buena prueba de ello es la traducción latina de dos verbos próximos como $\mu \varepsilon \tau \alpha v o \varepsilon ́ \omega$ y $\mu \varepsilon \tau \alpha \mu \varepsilon ́ \lambda o \mu \alpha \imath$ ('arrepentirse') que se vierten al latín, bien mediante el verbo paenitere, bien, lo más habitual, mediante distintas colocaciones verbo-nominales: paenitentiam agere / habere, paenitentiā ductus / motus.

Bajo esta aparente libertad en la traducción de la Vulgata, subyacen en realidad razones lingüísticas que justifican la elección concreta de cada colocación y de la doble construcción (personal e impersonal) de paenitere. El análisis de $\mu \varepsilon \tau \alpha v o \varepsilon ́ \omega$ y

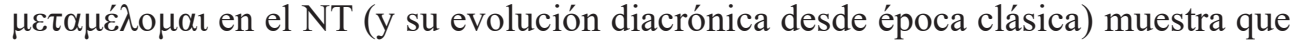
no son verbos sinóminos y que sus diferencias de significado, semánticas y sintácticas, resumidas en el Cuadro (3), tienen su cabal reflejo en la traducción de la Vulgata.

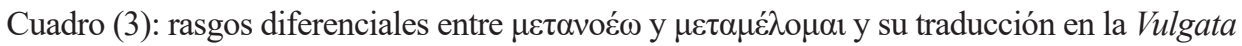

\begin{tabular}{|c|c|c|c|c|}
\hline & \multicolumn{2}{|c|}{ rasgos diferenciales } & \multicolumn{2}{|c|}{ traducción de la Vulgata } \\
\hline & significado & $\begin{array}{l}\text { semántica y } \\
\text { morfosintaxis }\end{array}$ & CVS & paenitere \\
\hline 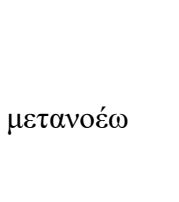 & $\begin{array}{l}\text { 'cambiar de opinión' } \\
\text { 'enmendarse' } \\
=\text { arrepentirse } 2 \text { (DRAE) }\end{array}$ & $\begin{array}{l}\text { Acción controlada, } \\
\text { volitiva e intencio- } \\
\text { nal. Sujeto Agente. } \\
\text { Usos imperativos e } \\
\text { impresivos }\end{array}$ & $\begin{array}{l}\text { paenitentiam } \\
\text { ago }\end{array}$ & $\begin{array}{l}\text { construcción } \\
\text { personal: } \\
\text { paeniteo }\end{array}$ \\
\hline$\mu \varepsilon \tau \alpha \mu \varepsilon ́ \lambda о \mu \alpha \imath$ & $\begin{array}{l}\text { ‘pesarle a alguien algo’ } \\
\text { ‘sentir remordimiento’ } \\
=\text { arrepentirse } 1 \text { (DRAE) }\end{array}$ & $\begin{array}{l}\text { Estado emocional, } \\
\text { verbo de senti- } \\
\text { miento. Sujeto Ex- } \\
\text { perimentador. } \\
\text { Voz media-anti- } \\
\text { causativa }\end{array}$ & $\begin{array}{l}\text { paenitentiam } \\
\text { habeo; } \\
\text { paenitentia } \\
\text { ductus / mo- } \\
\text { tus }\end{array}$ & $\begin{array}{l}\text { construcción } \\
\text { impersonal: } \\
\text { me paenitet }\end{array}$ \\
\hline
\end{tabular}

Mientras que $\mu \varepsilon \tau \alpha v o \varepsilon ́ \omega$ ('cambiar de opinión', 'enmendarse'), que expresa una acción intencional, controlada por un Agente, se traduce siempre por la CVS paenitentiam agere, semánticamente activa, $\mu \varepsilon \tau \alpha \mu \varepsilon ́ \lambda o \mu \alpha 1$, que expresa un sentimiento 
menos controlado ('sentir pesar, remordimiento'), aparece siempre en voz media (anticausativa) y se traduce bien por paenitentiam habere, bien por paenitentia ductus / motus, colocaciones estas últimas empleadas en latín postclásico y tardío como expresión léxica de diátesis pasiva con sustantivos que expresan sentimientos.

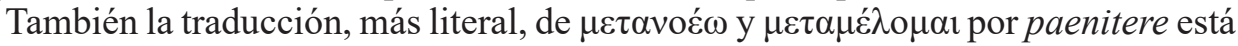
semánticamente motivada: en congruencia con las diferencias de significado entre los dos verbos griegos, se emplea la construcción impersonal (me paenitet) como

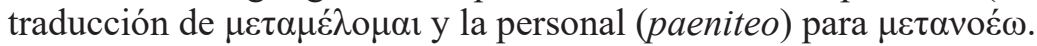

En definitiva, como ya señalara Hoffmann en su estudio de las construcciones causativas en la traducción de la Vulgata, «la comparaison d'un texte traduit avec son original permet des observations linguistiques importantes sur el système latin à l'époque de Jérôme» $(2014,170)$. Pero también sobre el texto griego mismo: las distintas posibilidades de traducción de la Vulgata hacen más explícitas las diferencias morfosintácticas y semánticas entre $\mu \varepsilon \tau \alpha \nu o \varepsilon ́ \omega$ y $\mu \varepsilon \tau \alpha \mu \varepsilon ́ \lambda o \mu \alpha$, diferencias que quedan en cambio difuminadas en su traducción en español por un verbo polisémico como 'arrepentirse'.

\section{Referencias bibliográficas}

Allan, R.J. (2003), The Middle Voice in Ancient Greek. A Study in Polysemy, Ámsterdam, Gieben.

B.D.A.G = Bauer, W. - Danker, F.W. - Arndt, W.F. \& Gingrich, F.W. (2000), A Greek-English Lexicon of the New Testament and other Early Christian Literature, Chicago-Londres, The University of Chicago Press.

Baños, J. M. (2003), «Paenitet y los verbos impersonales de sentimiento en latín: sintaxis y pragmática del acusativo personal», en Baños, J.M. et alii (eds.), Praedicativa: complementación en griego y en latín, Santiago de Compostela, Universidade de Santiago de Compostela, 51-77.

Baños, J. M. (2015a), «Bellum gerere y proelium facere: sobre las construcciones con verbo soporte en latín (y en griego)», en Muñoz, M.T. \& Carrasco, L. (eds.), Miscellanea Latina, Madrid, Sociedad de Estudios Latinos, 227-234.

Baños, J. M. (2015b), «Colocaciones verbo-nominales y traducción del griego al latín en el Nuevo Testamento: el Evangelio de San Mateo», en Floristán, J.M. et al. (eds.), Homenaje a I. Rodrígez Alfageme, Zaragoza, Pórtico, 61-72.

Baños, J. M. (2016), «Las construcciones con verbo soporte en latín: sintaxis y semántica», en Borrell, E. \& de la Cruz, O. (eds.), Omnia mutantur, Barcelona, vol. II, 3-27.

Baños, J. M. (en pr. a), «Verbo simple (paenitere) y construcción con verbo soporte (paenitentiam agere) en latín: a propósito de Quint. Inst. 9,3,12», en Álvarez-Pedrosa, J.A. et al. (eds.), Ratna. Homenaje a la profesora Julia Mendoza, Madrid, Escolar y Mayo.

Baños, J. M. (en pr. b), «Las construcciones con verbo soporte en latín: una perspectiva diacrónica», Journée d'étude. Les constructions à verb support en latin.

Baños, J. M. (en pr. c), «Las construcciones con verbo soporte en latín como rasgo de la lengua coloquial», XLVII Simposio de la Sociedad Española de Lingüistica.

Baños, J. M. \& Jiménez López, M.D. (2017), «'Odiar’ en el Nuevo Testamento (odi, odio sum, odio habeo): traducción y construcciones con verbo soporte en la Vulgata», Euphrosyne XLV. 
BDF = Blass, F. - Debrunner, A. \& Funk, W. (1961), A Greek Grammar of the New Testament and other Early Christian Literaturature, Chicago-Londres, The University of Chicago Press.

Bogaert, P.P. (1988), «La Bible latine des origines au Moyen Âge», Revue Théologique de Louvain 19, 137-159 y 276-314.

Bogaert, P.P. (2013), «The Latin Bible», en Paget, J.C. \& Schaper, J. (eds.), The New Cambridge History of the Bible, vol. 1: From the Beginnings to 600, Cambridge, CUP, 505526.

Burton, P.H. (2000), The Old Latin Gospels. A Study of their Texts and Language, Oxford, OUP.

Burton, P.H. (2013), «The Latin Version of the New Testament», en Ehrmann, B.D. \& Holmes, M.W. (eds.), The Text of the New Testament in Contemporary Research: Essays on the Status Quaestionis, Leiden-Boston, Brill, 167-200.

Conti, L. (2010), «Análisis del dativo en construcciones impersonales: los conceptos de sujeto y de semisujeto en griego antiguo», Emerita, 78, 2, 249-273.

Crespo, E. - Conti, L. \& Maquieira, H. (2003), Sintaxis del Griego Clásico, Madrid, Gredos.

Elliot, J. K. (1992), «The Translations of the New Testament into Latin: the Old Latin and the Vulgate», Aufstieg und Niedergang der römischen Welt, 26.1, Berlín, De Gruyter, 198-245.

Flobert, P. (1996), «Verbs supports en Latin», en Bammesberger, A. \& Heberlein, Fr. (eds.) Akten des VIII internationalen Kolloquiums zur lateinischen Linguistik, Heidelberg, Winter, 193-199.

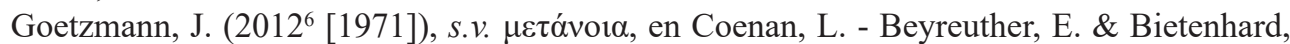
H. (eds.), Diccionario teológico del Nuevo Testamento, Salamanca, Ediciones Sígueme, vol. I, 334-337

Heikkinen, J.W. (1967), «Notes on 'epistrepho' and 'metanoeo'», The Ecumenical Review, 19, 3, 313-316.

Hoffmann, R. (1996), «Funktionsverbegefüge im Lateinischen», en Bammesberger, A. \& Heberlein, Fr. (eds.), Akten des VIII internationalen Kolloquiums zur lateinischen Linguistik, Heidelberg, Winter, 200-212.

Hoffmann, R. (2014), «Les constructions causatives dans les traductions latines des textes hébreux et grecs: le cas de la Vulgate de Jérôme», en Bortolussi, B. \& Lecaudé, P. (eds.), La causativité en latin, París, L'Harmattan, 143-174.

Hoffmann, J.B. \& Szantyr, A. (1965), Lateinische Syntax und Stilistik, Múnich, C. K. Beck.

Houghton, H.A.G. (2016), The Latin New Testament: A Guide to its Early History, Texts, and Manuscripts, Oxford, OUP.

Jiménez López, M.D. (2011), «El uso de $\pi$ oıє̃̃ $\sigma \alpha$ ı en Lisias: construcciones con verbo soporte», Linred, 9, 1-20.

Jiménez López, M.D. (2012), «Construcciones con verbo soporte, verbo simple y nombre predicativo: un ejemplo en griego antiguo», Minerva 25, 83-105.

Jiménez López, M.D. (2016.), «On Support Verb Constructions in Ancient Greek», Archivio Glottologico Italiano (e.pr.).

Jiménez López, M.D. (2017), «Las construcciones verbonominales con $\sigma 0 \mu \beta \varepsilon v \dot{\lambda}$ ıov en el Nuevo Testamento: un ejemplo de calco e interferencia lingüística», Habis (en pr.).

Jiménez Martínez, M.I. (2016), Colocaciones y verbos soporte en latín: sintaxis y semántica de pono, Tesis Doctoral (inédita), Madrid, UCM.

Jülicher, A. - Matzkow, W. \& Aland, K. (eds.) (1963-1972), Itala: Das Neue Testament in altlateinischer Überlieferung, vols. 1-4, Berlín, De Gruyter. 
Laubach, F. (20126 [1971]), s.v. غ̇ंı Bietenhard, H. (eds.), Diccionario teológico del Nuevo Testamento,Salamanca, Barcelona, Ediciones Sígueme, vol. I, 331-334.

López Martín, I. (2016), Las colocaciones verbo-nominales en latín y en griego: estudio comparado de César y Jenofonte, Tesis de Máster (inédita), Madrid, UCM.

Mayser, E. 1926-1938, Grammatik der griechischen Papyri aus der PtoleMäerzeit, Berlín-Leipzig, De Gruyter (reimp. 1970).

López Moreda, S. (1987), Los grupos lexemáticos de 'facio' y 'ago' en el latín arcaico y clásico: estudio estructural, León, Universidad de León.

Meershoek, G.Q.A. (1966), Le latin biblique d'après Saint Jérôme. Aspects linguistiques de la rencontre entre le Bible et le monde classique, Nimega-Utrecht, Dekker.

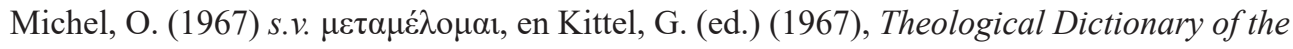
New Testament, vol. IV, Michigan, Eerdmans, 626-629.

Moreno Hernández, A. (1992), Las glosas marginales de Vetus Latina en las Biblias Vulgatas Españolas: 1-2 Reyes, Madrid, CSIC.

Nestle-Aland = Nestle, E. \& E. - Aland, B. \& K. (2014), Novum Testamentum Graece et Latine, Stuttgart, Deutsche Bibelgesellschaft.

Pinkster, H. (2015), The Oxford Latin Syntax. The Simple Clause, Oxford, OUP.

Real Academia Española (2009), Nueva Gramática de la Lengua Española (NGLE), 2 vols., Madrid, RAE.

Rosén, H. (1981), Studies in the Syntax of the Verbal Noun in Early Latin, Múnich, Fink, 130-159.

Thompson, E.F. (1908), METANOE $\Omega$ and METAMEAEI in Greek Literature until 100 A.D., including Discussion of their Cognates and of their Hebrew Equivalents, Chicago, The University of Chicago Press.

Tur, C., (2013), «Las construcciones de miseret y de misereor/miseror en latín», Cuadernos de Filología Clásica. Estudios Latinos 33, 2, 239-251.

Vineis, E. (1971-1974), «Studio sulla lingua dell'Itala», L'Italia Dialettale 34 (1971) 137248; 36 (1973) 287-372; 37 (1974) 154-166.

Weber, R. \& Gryson, R. (19944), Biblia Sacra iuxta Vulgatam versionem, Stuttgart, Deutsche Bibelgesellschaft.

Wordsworth, J. \& White, H.J. (eds.) $\left(1957^{2}\right.$ ), Novum Testamentum Latine. Editio minor, Oxford, Clarendon. 